\title{
Inequality in the 21st century: \\ A critical analysis of Piketty's work
}

\author{
Nadia Garbellini*
}

\section{Working Paper No. 69}

January 2018

\begin{abstract}
Thomas Piketty's (2014) Capital in the XXI Century aims to analyze distributions of income and wealth and their determinants, in a set of developed countries from the nineteenth century to the present. The objective is a bold one, made even more so by the fact that Piketty pursues it not only from a theoretical, but also, from an empirical point of view. The task is particularly impressive not only because of the enormous effort required in collecting and organising data, but also because the work entails attaching a deterministic interpretation to facts and figures from radically different countries over a time span that covers almost two centuries, thereby forcing comparison between numbers coming from clearly incommensurable contexts. These difficulties are not lost to Piketty, who states that "[w]ithout precisely defined sources, methods, and concepts, it is possible to see everything and its opposite." (Piketty, 2014, pp.2-3) This study argues that the empirical "methods and concepts' adopted by Piketty are not always consistent with those coming from his reference theoretical framework, nor from National Accounts (United Nations, 2009).
\end{abstract}

Keywords: Capital, Capital output ratio, Income distribution, Inequality, Growth theory, National accounts.

JEL Classifications: E01, E20, D30, D31, D33

* Università di Bergamo. nadia.garbellini@unibg.it 


\section{Introduction}

Thomas Piketty's (2014) Capital in the Twenty-First Century aims to analyze changes in distributions of income and wealth and their determinants, in a set of developed countries from the nineteenth century to the present. ${ }^{1}$

The objective is a bold one, and made even more so by the fact that Piketty pursues it not only from a theoretical, but also, from an empirical point of view. The task is particularly impressive not only because of the enormous effort required in collecting and organizing data, but also because the work entails attaching a deterministic interpretation to facts and figures from radically different countries over a time span that almost covers two centuries, thereby forcing comparison between numbers coming from clearly incommensurable contexts.

As stated elsewhere (see Garbellini and Wirkierman, 2014), real phenomena can be interpreted in light of a theoretical framework only if two issues are absolutely clear: (1) What question is the framework intended to answer? (2) What is the correspondence between theoretical and empirical magnitudes? Methodological and theoretical rigor is absolutely essential.

In other words, interpreting real phenomena through the lens of a theoretical framework requires defining theoretical magnitudes which correspond to theory on the one hand, and to available data on the other. One could of course try to stick to bare facts, avoiding any reference to theory. This, however, turns out to be even harder. This is especially true in the case of Piketty's studies, since he does not limit himself to providing an organic interpretation of facts and figures, but has built a whole dataset which he then uses for his analysis. Some empirical concepts that are central in National Accounts have been defined in relatively recent times, so that looking as far back as Piketty does in time and retrieving all the necessary pieces of information requires making assumptions that allow one to derive currently collected data from those collected one or more century ago.

The history of the development of international standards for national accounting is one of looking for the widest possible applicability for the highest possible number of countries. The task was not fully accomplished until 1993,1 and to a certain extent it is still work in progress. This should make it clear that the issue of inter-national-and even more so of inter-temporal comparisons, is a technically extremely complicated one, especially when the time span is as wide as that considered by Piketty.

These difficulties are not lost to Piketty, who states that "[w]ithout precisely defined sources, methods, and concepts, it is possible to see everything and its opposite." (Piketty,

\footnotetext{
${ }^{1}$ Piketty's 2017 Marshall Lectures have not as yet been published, but in the video version of his talks he does not appear to depart from the framework analyzed in this paper. See http://www.econ.cam.ac.uk/Marshall_Lecture/ThomasPiketty.html; accessed on January 6, 2018.
} 
2014, pp.2-3)

In the present article I am going to argue that the empirical 'methods and concepts' adopted by Piketty are not always fully consistent with those coming from his reference theoretical framework, nor from National Accounts (United Nations, 2009). In particular, Piketty sometimes mixes up equilibrium conditions, coming from a theoretical model, and accounting identities, which hold as such. Moreover, some of his empirical definitions are such as to make inter-temporal and international comparisons quite misleading.

The paper is organized as follows. Section 2 deals with the consistency of Piketty's methodological approach to theoretical and empirical definitions, as emerging from the System of National Accounts (SNA, hereinafter). Section 3 analyses the implications of Piketty's definition of wealth in terms of the institutional sectors involved and the way in which physical capital and other items, such as public debt securities, are dealt with in his framework. Section 4 briefly presents some of the key issues raised by the so called Cambridge Capital Controversy. Section 5 is a critical assessment of Piketty's 'second fundamental law of capitalism', also providing an alternative interpretation to the dynamics of capital/output ratios in France. Finally, Section 6 concludes.

\section{The notion of 'Capital'}

Let us start from Piketty's definition of Capital, which is the title of the book as well as a somewhat unsubtle reference to Marx's Das Kapital.

As is well known, there is no single theoretical paradigm in economics, but rather a number of them. In a nutshell, the whole variety of these can be classified in two broad categories, namely Classical and Neoclassical economics. Going into the details of the differences among the two is out of the scope of the present work. However, there is one common feature of the two theoretical approaches which is worth stressing: in both cases, fixed, physical capital is to be intended as productive capital, i.e. items to be installed and accumulated to serve as instrumental goods for the production of the final product. The accumulation of capital and its effects on growth and development has always been one of the main research topics for economists of both schools. ${ }^{2}$ In a few words, in both cases whether or not an asset can be classified as capital depends on whether or not such asset is used for the production of goods and services.

The definition of Capital provided by Piketty is entirely different:

In this book, capital is defined as the sum total of nonhuman assets that can be owned and

\footnotetext{
${ }^{2}$ This generic feature is the only common ground within the discussion between economists of the two schools about the nature and characteristic of capital, as the well known 'Cambridge Capital Controversy' shows all too well. More details about this in Section 4 below.
} 
exchanged on some market. Capital includes all forms of real property (including residential real estate) as well as financial and professional capital (plants, infrastructure, machinery, patents, and so on) used by firms and government agencies.

(Piketty, 2014, p. 46)

Of course, this is the first, the main, and the most common criticism that has been leveled against Piketty's approach, a criticism that comes not only from non-neoclassical economists, but also from a highly respected neoclassical economist Robert Solow, in his review of Piketty's book:

There is a small ambiguity here. Piketty uses "wealth" and "capital" as interchangeable terms. We know how to calculate the wealth of a person or an institution: you add up the value of all its assets and subtract the total of debts. [...] The result is net worth or wealth. In English at least, this is often called a person's or institution's capital. But "capital" has another, not quite equivalent, meaning: it is a "factor of production," an essential input into the production process, in the form of factories, machinery, computers, office buildings, or houses (that produce "housing services"). This meaning can diverge from "wealth." Trivially, there are assets that have value and are part of wealth but do not produce anything.

(Solow, 2014)

Piketty (2014, p. 47) recognizes the relevance of "the boundary line between accumulation and appropriation", as well as the fact that "it would be better to reserve the word "capital" to describe forms of wealth accumulated by human beings (buildings, machinery, infrastructure, etc.) and therefore to exclude land and natural resources, with which humans have been endowed without having to accumulate them". However, he not only justifies his choice by saying that making such a distinction would entail valuation problems, but also adds that it is "neither desirable nor practical [...]. Capital in all its forms has always played a dual role, as both a store of value and a factor of production. I therefore decided that it was simpler not to impose a rigid distinction between wealth and capital." (Piketty, 2014, p. 48, emphasis added)

It is therefore a well established fact that the definition of Capital as a synonym of wealth does not comply with theoretical definitions of either approach. But what about compliance to national accounting standards? According to United Nations (2009):

At the heart of the SNA is the production of goods and services. These may be used for consumption in the period to which the accounts relate or may be accumulated for use in a later period. In simple terms, the amount of value added generated by production represents GDP. The income corresponding to GDP is distributed to the various agents or groups of agents as income and it is the process of distributing and redistributing income that allows one agent to consume the goods and services produced by another agent or to acquire goods and services for later consumption.

(United Nations, 2009, p. 2, emphasis added) 
The logic is clear, especially when looking at the sequence of non-financial accounts. The production of goods and services generates GDP, i.e. primary incomes, which are defined as "incomes that accrue to institutional units as a consequence of their involvement in processes of production or ownership of assets that may be needed for purposes of production." (United Nations Statistics Division, 2016, emphases added) GNI is then obtained by adding to GDP the net balance with the rest of the world of primary incomes payable and receivable, and of net property incomes payable and receivable. Net property incomes are "incomes receivable from the ownership of financial or tangible non-produced assets (mainly land or sub-soil assets)" (United Nations Statistics Division, 2016). Finally, the balance of current transfers received and paid determine disposable income. In a closed economy, all the three concepts of income would be equivalent to GDP, which is the true new income generated in each accounting period through production of goods and services. It is worth stressing that GDP includes wages and profits, ${ }^{3}$ which accrue to the corresponding institutional units due to their involvement in production (wages) and the ownership of the means of production (profits). Property income, which is ultimately rents, is something entirely different, and as such is kept separated from profits by national accountants. The difference is subtle but apparent: profits are due to the ownership of produced assets necessary for production activity to be carried on, while property incomes are due to the ownership of financial or tangible non-produced assets. In the first case, the flow of income is justified by the fact that assets are productively employed and therefore generate new income. In the second case, the flow of income derives from the fact that the assets are put at the disposal of another institutional unit for purposes other than productive activity. As the two kinds of income are kept separated being deeply different in their nature, so should the two kinds of assets giving rise to them.

To summarize, Piketty defines Capital as the sum of the value of produced and nonproduced physical assets, plus the net financial worth. Income is defined as net national income, i.e. GNI net of depreciation. ${ }^{4}$ After giving these definitions, Piketty introduces the concept of Capital/Income ratio $(\beta)$ as the ratio of the stock of capital to the annual flow of national income (Piketty, 2014, pp. 50 and ff.). In this way, Piketty pretends to introduce a numéraire allowing for inter-temporal and inter-national comparisons: the value of capital stock is measured not in monetary terms, but in terms of years of national income.

It is even clearer when looking at the criterion adopted by the SNA to record the transfer of products between units. United Nations (2009) explicitly distinguishes between legal ownership and economic ownership. The legal owner of an entity is "the institu-

\footnotetext{
${ }^{3}$ Or better, 'operating surplus and mixed income'.

${ }^{4}$ Piketty adopts a particular definition of national wealth, i.e. the sum of private and public wealth, whereas private wealth corresponds to the institutional sector Households only. This issue will be the subject of section 3 .
} 
tional unit entitled in law and sustainable under the law to claim the benefits associated with the entities", whereas the economic owner is "the institutional unit entitled to claim the benefits associated with the use of the entity in question in the course of an economic activity by virtue of accepting the associated risks." (United Nations, 2009, p. 41, emphasis added). An example is then provided clarifying the difference between the two kinds of ownership: "when a bank legally owns a plane but allows an airline to use it in return for an agreed sum. It is the airline that then must take all the decisions about how often to fly the plane, to where and at what cost to the passengers. The airline is then said to be the economic owner of the plane even though the bank remains the legal owner. In the accounts, it is the airline and not the bank that is shown as purchasing the plane. At the same time, a loan, equal in value to payments due to the bank for the duration of the agreement between them is imputed as being made by the bank to the airline." (United Nations, 2009, p. 20) Once again, it is the employment of an item of fixed capital as part of a production process which identifies the corresponding owner: the economic owner will be entitled to the profits emerging for such a production activity, while the legal owner is entitled to a rent paid by the economic owner according to a legal agreement between the two units.

Piketty's capital/income ratio recalls the capital/output ratio commonly used as an indicator of capital intensity (see Pasinetti, 1981). Again, Piketty's concept does not correspond to the usual meaning attached to such a ratio within growth theory; in this latter case, in fact, capital intensity is the ratio of the value of installed, accumulated productive capital to the quantity of net output which it is able to generate. On the contrary, in Piketty's case it is simply the ratio of the value of national wealth divided by the flow of net national income, which is meaningless in growth-theoretical terms. Let us clarify this issue. In both cases we are dealing with the ratio of a stock to a flow, evaluated at current (monetary) values. The usual capital/output is the ratio of the stock of productive capital to the net product that is generated by using such capital as means of production. The meaning is therefore straightforward: it is the stock of capital that proved to be necessary, in a given accounting period, to generate one (monetary) unit of net product. ${ }^{5}$ The numerator and the denominator are perfectly comparable: the stock of means of production per unit of net production itself.

Let us now consider Piketty's capital/output, or wealth/income, ratio. It is not an indicator of some technological characteristic of the production process, but a measure of the relative relevance of accumulated wealth with respect to the annual flow of national

\footnotetext{
${ }^{5}$ It is worth stressing that the concept of net product is not equivalent to that of GDP: the first is given by the value of final uses, i.e. the difference between domestic total and intermediate uses. In order to get GDP, one has to subtract the value of imported intermediate uses and add taxes less contributions on final products. GDP can be computed at the aggregate level only - and only at the aggregate level is equivalent to value added at basic prices. At the sectoral level, GDP cannot be computed and the equivalence breaks.
} 
income-Piketty's argument is that countries with relatively higher wealth/income ratios have a stronger tendency to generate income and wealth inequality. Hence, the meaning attached to such a ratio is entirely different from the one stated above, and it can hardly be interpreted in the light of the theoretical framework advocated by Piketty himself and, in general, within the realm of growth theory.

\section{National wealth and institutional sectors}

The main methodological issues concerning measurement and definitions are not included in Piketty (2014), but discussed in Piketty and Zucman (2014). Here, the authors address the issue of alternative definitions of wealth, distinguishing between market value and book value national wealth. More precisely, market value national wealth "simply sums private and government wealth. The capital stock of corporations is included in national wealth through the equity holdings of households and the government." On the contrary, book value national wealth "sums all the nonfinancial assets [...] of all domestic sectors and adds the net foreign asset position. [...] By definition, book-value national wealth is also equal to market-value national plus the net wealth of the corporate sector. So the two measures coincide when the net wealth of the corporate sector is zero, or, equivalently, when Tobin's Q is equal to 1." (Piketty and Zucman, 2014, pp. 27-8)

The authors then concentrate on the first measure, "because it is a concept closer to the one used by the economists of the 18th, 19th, and early 20th centuries." (Piketty and Zucman, 2014, p. 28) On the contrary, as stated by the authors themselves, the definition emerging from the SNA is that of book value national wealth: "For the economy as a whole, the balance sheet shows the sum of non-financial assets and net claims on the rest of the world. This sum is often referred to as national wealth." (United Nations, 2009, p. 257)

It is worth devoting a few lines to analyzing the implications of such a definition of national wealth. As stated above, Piketty's definition of national wealth only includes the net worth of the private sector, defined as Households and NPISH (non-profit institutions serving households) plus the net worth of General Government. The institutional sector of Corporation is therefore excluded from the computation of national wealth. According to Piketty and Zucman, the capital stock of corporations is completely included in the market value of equities and corporate bonds possessed by the private sector. This is of course true whenever Tobin's Q is equal to 1, i.e. when the net worth of financial corporations is 0 or, equivalently, when financial net worth is equal to the value of non-financial assets. In other words, when the market value of corporations is equal to the replacement cost of their installed productive capacity. In fact, net worth $(N W)$ is given by non-financial 
assets $(N F A)$ plus financial assets $(F A)$ minus liabilities $(F L)$, the difference between financial assets and liabilities being financial net worth $(F N W)$ :

$$
N F A+F A-F L=N F A+F N W=0, \quad N F A=-F N W, \quad-\frac{F N W}{N F A}=1
$$

There is no reason for this equality to hold. The idea at the heart of Tobin's Q is once again a long run general equilibrium one. If a company is characterized by $Q<1$, then its market value is lower than the replacement cost of its installed productive capacity. Potential competitors would therefore find it more convenient to purchase it rather than creating a new company. This would increase stock prices, thereby driving up $Q$ to the point where it is equal to 1 . Conversely, a higher-than-one value of $Q$ would indicate that a firm is earning a rate that is higher than replacement cost for its installed capital. This would induce potential competitors to enter the market, reducing incumbents market shares and hence their stock price, to the point where $Q=1$.

But we know by now that stock prices are more and more disconnected from company's real, productive activity. Moreover, companies do hold shares of other companies, as well as a number of other financial assets, which makes it really heroic to connect replacement cost of capital, financial net worth, and stock prices. Taking such an equality for granted - or attributing its failure to measurement problems, as Piketty and Zucman do-is even bolder when using a definition of national wealth based on such an assumption for international and intertemporal comparisons. In fact, financialization proceeded at different paces in different countries, so that the gap between market value of companies and the value of their non-financial assets opened up in a very asymmetric way-and, in the same time period, such a gap might be extremely wide in some countries, while much narrower in other countries. Moreover, Piketty's definition of national wealth mixes up legal and economic ownership of physical assets, and hence breaks the above mentioned fundamental distinction made by National Accounting.

Again, the Households and NPISH sector includes all non-incorporated business, hence accounting for the value of its productive capital. Excluding the sector of Corporations means disregarding a relevant part of a nation's productive capital, i.e. that owned by corporations. This also makes intertemporal and international comparisons extremely unreliable. One can imagine the share of corporated to total businesses to be much higher, e.g., in the US than in Italy, and much higher in Italy today than one hundred years ago. The very fact that this proportion varies makes the share of disregarded capital to vary for country to country and from year to year.

There is a final, though very important, remark to be made about Piketty's definition of national wealth. One can accept that Piketty's aim is totally different from that of traditional growth theory, and that it is impossible to attach to his wealth/income ratio 
the usual theoretical meaning. Hence, one can follow Piketty and try to see this ratio as providing different pieces of information than the usual ones. However, while it is possible to do so in analyzing the evolution of such a ratio within a single institutional sector, accepting Piketty's definition for a nation as a whole entails a further, extremely relevant drawback.

More specifically, the Corporation sector includes both financial and non-financial corporations, the former including banks. In other words, Financial Corporations also include the Central Bank, and hence its own asset and liabilities. Recalling that public debt of course corresponds to private credits whenever public bonds are held by the private sector as defined by Piketty, debts and credits cancel out and there is no change in national wealth, in whatever way we define it. Similarly, when public bonds are held by foreign entities, national wealth includes only the General Government debt, while the credits are registered elsewhere, so that this represents a loss of national wealth. Accepting Piketty's definition of national wealth implies treating the banks as foreign units: were they to hold public bonds, this would immediately translate into a loss of national wealth, whereas accounting rules would imply registering the corresponding credit and hence leaving national wealth unaltered. This has straightforward and relevant policy implications. Accepting Piketty's definition implies accepting the idea that the Central Bank, or public banks in general, should not hold public debt securities, since this would impoverish the country. This has obvious consequences when introduced into the political debate.

This has implications for Piketty's comparisons as well. For example, intertemporal comparisons concerning Italian national wealth defined as Piketty does makes it hard to compare the period when the Bank of Italy acted as last resort lender for the Treasury, buying public bonds and thus keeping interest rates low, to the following years. It is also hard to compare Japan, where the Central Bank still has the power to do so, to other countries where this is not possible any more. The case of Germany is also peculiar, given that public banks - other than the Central Bank, which would be against the Treaties-still act as last resort lenders buying relevant amounts of public bonds.

\section{A detour: the Cambridge Capital Controversy}

Piketty's treatment of Cambridge Capital Controversy (see Piketty, 2014, pp. 230-232) is an excellent example of what Petri (2007, p. 599) defined as the attitude of neoclassical economists towards "the unwillingness to make the effort to understand (or even only to read) the opponents' arguments, which has characterized the neoclassical contributions to the capital debates since the mid-1970s." 
Differently from Solow (1963) and Samuelson $(1966),{ }^{6}$ who carefully read their opponents' argument and hence admitted — more or less plainly — the 'defeat', before trying to argue that it could be sidestepped without the core of neoclassical theory being in jeopardy, Piketty shows an almost complete lack of acquaintance and labels the whole controversy"[i]f one rereads the exchanges [...] with the benefit of hindsight"-as a "debate, which at times had a marked post-colonial dimension" and "did more to cloud economic thinking than to enlighten it."

According to Piketty, the origin of the controversy goes back to the very first formulation of what he calls the second fundamental law of capitalism, first by Roy Harrod (1939) and then by Evsey Domar (1948), who did "invert it as $g=s / \beta$." In order to have equilibrium growth (in the sense of full utilization of productive capacity and full employment), the rate of growth itself must be equal to $s / \beta$ on the one side, where $\beta$ is determined by the technique in use, and to the rate of growth of population and labor productivity on the other. "[I]t follows that growth is an intrinsically unstable process, balanced 'on a razor's edge'." (Piketty, 2014, pp. 230-231) Harrod's conclusion, though not entirely wrong, is too tight according to Piketty, since it leaves no room for adjustments between the involved magnitudes.

Then, Piketty continues, Domar (1948) could arrive at a more "optimistic and flexible version of the law", where $s$ and $\beta$ can to a certain extent adjust to each other. At last, Solow (1956) made the most important step, by introducing "a production function with substitutable factors, which made it possible to invert the formula and write $\beta=s / g$ ", and hence showing that "in the long run, the capital/income ratio adjusts to the savings rate and structural growth rate of the economy rather than the other way around."

Actually, as Pasinetti (1974) explains all too well, Harrod's contribution can be seen as log- ically following, even if preceding temporally, ${ }^{7}$ that of Domar. In fact, Domar's idea was that of looking for the condition for long-run equilibrium growth. This was obtained by singling out the idea that investments act through two channels: they add up to aggregate demand on the one side, and to the existing stock of capital on the other side. Hence, equilibrium growth requires, period after period, additions to net output to be equal to additions to productive capacity. Hence, by equating these two magnitudes, he determined what he called the warranted rate of growth of investments, $g=s / \beta$. $\beta$ and $s$ being constant, output, consumption and productive capacity expand at the same rate.

\footnotetext{
6 "Pathology illuminates healthy physiology. Pasinetti, Morishima, Bruno-Burmeister-Sheshinski, Garegnani merit our gratitude for demonstrating that reswitching is logical possibility in any technology. [...] If this causes headaches for those nostalgic for the old parables of neoclassical writing, we must remind ourselves that scholars are not born to live an easy existence. We must respect, and appraise, the facts of life." (Samuelson, 1966, p. 582-83)

${ }^{7}$ Actually, Harrod expounded his theoretical framework in more detail in his 1948 book.
} 
However, Domar did not make any distinction between full employment of the labor force and full utilization of productive capacity, therefore implicitly assuming that one implies the other, which can be realistic in the short run only. "It is at this point that Harrod's contribution may be brought in" (Pasinetti, 1974, p. 95); actually, what he did was to add a further condition to those stated by Domar, namely that the natural rate of growth $g_{n}$ - the maximum rate of growth attainable given technical conditions-has to be equal to the sum of population and labor productivity (i.e. output per worker) growth. The condition for long-run equilibrium, the one which then became known as 'Harrod-Domar equation', therefore emerged as $g_{n}=s / \beta$. This has not to be seen as a positive relation, describing what happens in an actual economic system, but rather as a normative relation, i.e. an equilibrium condition.

Solow's contribution is not a continuum of, but rather in opposition to that of Harrod and, most of all, Domar:

\begin{abstract}
A remarkable characteristic of the Harrod-Domar model is that it consistently studies long-run problems with the usual short-run tools. One usually thinks of the long run as the domain of the neoclassical analysis, the land of the margin. Instead Harrod and Domar talk of the long run in terms of the multiplier, the accelerator, "the" capital coefficient. The bulk of this paper is devoted to a model of long-run growth which accepts all the Harrod-Domar assumptions except that of fixed proportions.
\end{abstract}

(Solow, 1956, p. 66)

His conclusion was that "when production takes place under the usual neoclassical conditions of variable proportions and constant returns to scale, no simple opposition between natural and warranted rates of growth is possible. There may not be-in fact in the case of the Cobb-Douglas function there never can be-any knife-edge. The system can adjust to any given rate of growth of the labor force, and eventually approach a steady proportional expansion." (Solow, 1956, p. 73)

Actually, the crucial variable for adjustment along a balanced-growth path is not the capital/output, but rather the capital/labor ratio $k=K / L$. In a few words, adjustment works as follows: given the rate of growth of labor supply-i.e. the rate of growth of population - the wage rate adjusts through the marginal productivity principle so that all available labor is employed. With substitutable factors (and constant returns to scale), the production function can be reformulated as an equation in the only variable $\mathrm{k}$, giving the amount of output that can be obtained by combining one unit of labor with varying amounts of capital. Again, the marginal productivity principle makes real rental for capital services adjust in order to make capital itself fully utilized. "The warranted rate of growth, warranted by the appropriate real rate of return to capital, equals the natural rate." (Solow, 1956, p. 70) 
Balanced growth is realized when capital per worker is constant over time. With a well behaved production function, this boils down to the determination of the equilibrium level of the capital/labor ratio $k^{*}$, which is always reached whatever its initial value via the usual neoclassical mechanism.

In any case, Piketty considers Solow's as the last word on this, so much so that he ascertains with some surprise that controversy "continued, however, in the 1950s and 1960s between economists based primarily in Cambridge, Massachusetts (including Solow and Samuelson, who defended the production function with substitutable factors) and economists working in Cambridge, England (including Joan Robinson, Nicholas Kaldor, and Luigi Pasinetti), who (not without a certain confusion at times) saw in Solow's model a claim that growth is always perfectly balanced, thus negating the importance Keynes had attributed to short-term fluctuations. It was not until the 1970s that Solow's so-called neoclassical growth model definitively carried the day."(Piketty, 2014, p. 231-232, emphasis added)

The core of Cambridge Capital Controversy, however, was not Solow's model of growth, but rather neoclassical production function and, particularly, the way in which capital is dealt with in that framework. Robinson (1953) rushed into the debate with her paper The Production Function and the Theory of Capital. To put it simply, neoclassical theory determines distributive variables and prices through the aggregate production function. In a one-commodity world, capital can in principle be expressed in physical terms with no need of aggregation. In a world with heterogenous commodities, however, this is not possible anymore, ${ }^{8}$ and aggregation requires expressing it in terms of value. A problem of circularity therefore arises, since capital requires knowing prices to be measured, and at the same time is a determinant of them.

Robinson's paper-which was in turn stimulated by a letter by Sraffa as early as 1936 - elicited a great deal of literature criticizing marginalist treatment of capital, which culminated in Sraffa's (1960) Production of Commodities by Means of Commodities and his demonstration of reswitching and capital-reversal. Before going into some detail, a small step forward is necessary, to Samuelson's (1962) surrogate production function article, in which he claimed that the results of the one-commodity model could be extended to the "quasirealistic MIT model of diverse heterogeneous capital goods" (p. 202) as well, and stated what he called three 'parables': (i) real return on capital is univocally determined by its marginal productivity; (ii) increasing quantities of capital are associated to

\footnotetext{
${ }^{8}$ In fact, marginal theory takes both the factors endowment and alternative production techniques as given. Since capital goods enter in both, but in different proportions and with different roles-think of fixed as opposed to circulating capital-a common unit of measurement cannot be devised different than value. The fact of endowments being given is crucial to neoclassical theory of prices, since they are derived as an index of relative scarcity.
} 
decreasing marginal productivity and hence real return on capital itself; (iii) distributive variables depend on relative factor scarcities and marginal products. The occurrence of reswitching and capital-reversal with heterogenous capital goods violates the three parables.

Reswitching takes place when the cost-minimizing technique is $a\left(K_{a} / L_{a}\right)$ in correspondence of two different rates of interest- $r_{l}$ and $r_{h}{ }^{9}$ - and $b\left(K_{b} / L_{b}\right)$ in correspondence of intermediate interest rates $r_{i}$ in $\left(r_{l}, r_{h}\right)$. Hence, when the interest rate-i.e. the real return on capital-decreases from $r_{h}$ to $r_{i}$ to $r_{l}$, the choice of technique switches from a to $\mathrm{b}$ and then reswitches to a again. This means that the same capital/labor ratio, i.e. the same technique, is employed in correspondence of two different interest rates, which violates parables (i) and (ii).

The phenomenon of capital-reversal takes place when, comparing two equilibrium positions, the one characterized by the lower capital/labor-i.e. the one in which capital is more scarce relatively to labor-ratio is also characterized by the lower interest rate, which violates parables (ii) and (iii).

A few years later Samuelson's pupil, David Levhari (1965), maintained he could show that Sraffa's argument was wrong, and that reswitching could take place in an industry but not in the economic system as a whole. Sraffa immediately reacted by asking Luigi Pasinetti to show Levhari's claim was wrong, which Pasinetti promptly did during the First World Congress of the Econometric Society, held in Rome in the same year. After the conference, Levhari and his colleagues at MIT tried to challenge Pasinetti's proof by claiming that the result crucially depended on whether the matrix describing the technique in use was assumed to be reducible or not. Pasinetti then showed that his proof was valid in both cases, and the revised paper (Pasinetti, 1966) was published in 1966 in a memorable issue of the Quarterly Journal of Economics. In the same issue, among the others, two articles by Samuelson (1966) and Levhari and Samuelson (1966) were published. The latter was titled The nonswitching theorem is false; the former starts by saying that

The phenomenon of switching back at a very low interest rate to a set of techniques that had seemed viable only at a very high interest rate involves more than esoteric technicalities. It shows the simple tale told by Jevons, Bohm-Bawerk, Wicksell, and other neoclassical writers - alleging that, as the interest rate falls in consequence of abstention from present consumption in favor of future, technology must become in some sense more "roundabout," more "mechanized," and "more productive" — cannot be universally valid.

(Samuelson, 1966, p. 568)

In the same article, he offered an explanation of why such 'paradoxes' could occur by adopting the Austrian definition of capital as time. The example chosen was that of

\footnotetext{
${ }^{9}$ Where subscript $h$ stands for 'high' and $l$ for 'low': $r_{h}>r_{l}$.
} 
production of champagne by means of labor and time alone. The controversy of course continued, as an exchange between Joan Robinson, Solow, Pasinetti and many others. ${ }^{10}$ At the end of the day, as Piketty stresses, it was the neoclassical side that won the match. They could not resolve the theoretical shortcomings, but they could take advantage of the critics to pile up additional hypotheses, which obscured the crucial issues, and continued to produce theoretical and empirical literature which finally became dominant. The profession simply ignored Cambridge, UK criticisms, or relegated them to the role of 'paradoxes' or 'pathologies', and pressed ahead.

Making the whole controversy boil down to an issue of how to quantitatively deal with physical capital, however, would be to understate the issue. Even more important than that of measurement is the problem of the different meaning of capital in the two approaches.

In Neoclassical theory, capital is simply a factor of production, in the same way as labor. Distributive variables, i.e. the wage rate and the rate of interest-which are equivalent to the rate of profit, or real return on capital - are simply given by technology and computed as factors' marginal productivity. The accumulation of capital simply allows the adoption of more roundabout, more mechanized, and hence more productive techniquesas quoted from Samuelson a few lines above.

This increasing roundaboutness causes the rate of interest to fall, as a consequence of "abstention from present consumption in favor of future." Hence, wages are the remuneration for making labor available to the production process, profits are the reward for postponing consumption, and both are endogenously determined by purely technological factors. In essence, more capital means more roundabout techniques, which allow for the extraction of more output from the same inputs. Neither conflict nor class struggle characterize capitalist society as it is described by the Neoclassical model(s). Profits and wages are perfectly symmetric concepts as they are both technically given factor remunerations.

On the contrary in Classical theory-and of course in Marxian theory in particularcapital is first of all a relation of production. More precisely, it is a property relation: monopoly ownership of the means of production enables the owners-i.e. the capitaliststo appropriate the surplus value generated by labor in the production process. Distributive variables are not determined by technology, i.e. technical relations of production, but by class struggle. In fact, Classical/Sraffian theory takes them as exogenous, rather than as endogenously given as Neoclassicals do. Increasing roundaboutness is an integral part of technical relations of production, which allows for the extraction of more and more surplus value as profits, thereby increasing exploitation. This is the very logic that forms the basis for the working of a capitalist economy, and hence capital is a fundamental category in the analysis of the capitalist mode of production. Wages and profits are not symmetric at all.

This crucial difference in the way of understanding capital as a category for the study

\footnotetext{
${ }^{10}$ For a review, see Harcourt (1972) and Bliss (1975).
} 
of capitalist societies is also reflected in the way of conceiving, and hence also measuring, profits. As stated above, profits in neoclassical theory are just the remuneration of one factor of production, namely capital, according to its relative scarcity. On the contrary, for Classical economists the concept of profits is closely connected to that of surplus, i.e. the difference between the net output produced and the necessary costs of production. Within this approach, when limiting ourselves to considering technical conditions of productioni.e. the way in which an economic system reproduces itself period after period-no concept such as profits emerges at all. The magnitude which is actually relevant is that of surplus, computed as a residual after deducting wages from net output.

\section{The second fundamental law of capitalism}

Once it has been clarified that Piketty's $\beta$ cannot be interpreted, as it has always been by both classical and neoclassical economics, as describing the technology in use and its growth potential, we can try to look at it from a different point of view. Specifically, which meaning, if any, can be attached to such a ratio, and is Piketty's interpretation consistent with a different interpretation of it?

In Piketty's argument, the role played by what he calls the 'second fundamental law of capitalism' is of great importance:

In the long run, the capital/income ratio $\beta$ is related in a simple and transparent way to the savings rate $s$ and the growth rate $g$ according to the following formula: $\beta=s / g$

$[\ldots]$ This formula, which can be regarded as the second fundamental law of capitalism, reflects an obvious but important point: a country that saves a lot and grows slowly will over the long run accumulate an enormous stock of capital (relative to its income), which can in turn have a significant effect on the social structure and distribution of wealth.

(Piketty, 2014, p. 166, emphases added)

It is first of all important to clarify the meaning of long run in the present-neoclassicalcontext. When referring to a key variable or ratio, its long run value is the particular value that ensures stability. In the case of a ratio, its long run value is that particular combination of the value of the numerator and denominator which, multiplied by the corresponding rate of growth, ensures its stability. Moreover, a long run equilibrium value is a stable equilibrium: any deviation is automatically corrected, and an initial value greater or smaller than the equilibrium one is automatically bound to smoothly reach it.

In other words, Piketty is basically looking for the condition for $\beta$ to be stable through time. 
Given that $\beta=K / Y$, the variation of $\beta$ is given by:

$$
\dot{\beta}=\frac{\mathrm{d}}{\mathrm{dt}}\left(\frac{K}{Y}\right)=\frac{\dot{K} Y-K \dot{Y}}{Y^{2}}=\frac{\dot{K}}{Y}-\frac{K}{Y} \frac{\dot{Y}}{Y}=\frac{K}{Y} \frac{\dot{K}}{K}-\frac{K}{Y} \frac{\dot{Y}}{Y}=\beta\left(\frac{\dot{K}}{K}-\frac{\dot{Y}}{Y}\right)
$$

Hence, the condition for $\beta$ to be stable, i.e. $\dot{\beta}=0$, is that wealth and income grow at the same rate:

$$
\frac{\dot{Y}}{Y}=\frac{\dot{K}}{K}
$$

Which is the value of $\beta$ which ensures that condition (1) is satisfied? If $\dot{K}=s Y^{11}$ and $\dot{Y}=g Y$, the previous expression can be written as:

$$
\frac{s Y}{K}=\frac{g Y}{Y}, \quad s \frac{Y}{K}=g, \quad s=\beta^{*} g, \quad \beta^{*}=s / g
$$

When $\beta<\beta^{*}$, then $\dot{\beta}>0$ : all the rest being equal, $\beta$ is going to increase; its growth stops when $\beta=\beta^{*}$. The opposite happens when $\beta>\beta^{*}$. This, of course, provided that $s$ and $g$ are constant over time: the equilibrium is stable, and the system tends to reach it.

In other words, were we to freeze the current situation - the rate of growth of income and the rate of savings out of it-forever, the ratio of wealth to income would gradually converge and then stabilize. $\beta$ is the end point of this convergence process.

Piketty's is the usual neoclassical interpretation: an economic system is subject to secular forces, which left to themselves would lead it to reach long run equilibriumthose forces which, according to Piketty, push towards convergence-and to short run, short-lived shocks which disturb this convergence process, though without changing the long run trajectory-i.e. push towards divergence:

[T] he law $\beta=s / g$ does not explain the short-term shocks to which the capital/income ratio is subject $[\ldots]$ but it does allow us to understand the potential equilibrium level toward which the capital/income ratio tends in the long run, when the effects of shocks and crises have dissipated.

(Piketty, 2014, p. 170)

However, it should be clear that a long run equilibrium value, when intended in this way, should be unique. Instead, since $s$ and $g$ are anything but constant, $\beta$ itself is continuously changing, which is inconsistent which contradicts the very notion of long run explained above.

\footnotetext{
${ }^{11}$ Here, $s$ is to be intended as the rate of net saving, i.e. the ratio of gross savings net of depreciation to income
} 
Incidentally, this closely connects to the controversy dealt with in the previous Section. One of the very first criticisms made to neoclassical growth theory by economists in Cambridge (UK) precisely concerns the notion of long run equilibrium and of the transition to it. More precisely, the very idea of long run equilibrium is somehow paradoxical: either an economic system actually is and has always been in equilibrium, or it finds itself in a state of disequilibrium. It is the very notion of long run equilibrium value which is itself changing period after period, meaning that none of them can actually be reached. This makes the notion of convergence on an equilibrium position devoid of logical meaning.

Piketty provides an analysis of the historical evolution of $\beta$ in eight developed countries. The conclusion he draws is that $\beta$, after a marked decrease after WWII due to the destruction of physical capital brought about by the war, is now increasing again, getting closer to its historical norm. This "capital comeback" is due to many reasons: a tendency to lower rates of growth $g$, demographic reasons, and a relatively higher $s$, which makes the ownership of capital - and hence inheritance - more and more relevant in the determination of national income. He then stresses the importance of a coordinated effort to tax wealth in order to avoid sliding backwards to a XIX century like situation, with wealth concentrated in the hands of a few people who inherited it, hence hampering social mobility.

Is it possible to attach some alternative interpretation to $\beta$, if necessary slightly changing its specification, and in which way does it differ from Piketty's?

\subsection{Alternative definitions of income}

First of all, it is necessary to go back to the different definitions of income. GNI is the sum of primary incomes, i.e. wages and profits and net property income, and is the balancing item of the Allocation of Primary Income Account. It describes the distribution of primary incomes as they accrue to the corresponding recipients. On the contrary GDP, i.e. the balancing item of the Production account, and the opening item of the Generation of income account, is the sum of wages and profits as they are paid, i.e. as the surplus generated in production activity. When related to the corresponding capital, it basically describes how these stocks actually generate the flows of income. The logic at the basis of this comparison is that accumulation generates income, and hence savings.

On the contrary, disposable income is the balancing item of Secondary Distribution of Income Account. It is given by GNI after taxes on income and wealth, social contribution, and net current transfers to the rest of the world. It describes the distribution of income as it is reallocated after being generated, and it represent income as it is actually available for consumption and savings. Hence, when related to the corresponding kind of wealth it describes the way in which flows of savings out of income actually determines the change 
in stocks. The logic being that savings generate investments, and hence accumulation.

It is rather clear that Piketty's analysis is of the second type - the former being closer to classical and Keynesian point of view. Therefore, the concept of income which should be consistently used to carry it on is that of disposable income, not that of GNI as Piketty does. 1 Moreover, consistently with National Accounts, some slight modifications of Piketty's original formulation are needed.

\subsection{Explicitly acknowledging depreciation}

First of all, as stressed above, Piketty explicitly defines $s$ as the rate of net savings. The latter is the ratio of gross savings less depreciation to income. Gross savings can be defined as the gross rate of savings, $\sigma$, times income: ${ }^{12} G S \equiv \sigma Y$. Formally:

$$
s=\frac{\sigma Y-\delta K}{Y}=\sigma-\delta \beta
$$

Expression (2) can therefore be rewritten as:

$$
g=\frac{s}{\beta^{*}}, \quad g=\frac{\left(\sigma-\delta \beta^{*}\right)}{\beta^{*}}=\frac{\sigma}{\beta^{*}}-\delta, \quad g+\delta=\frac{\sigma}{\beta^{*}}
$$

and hence:

$$
\beta^{*}=\frac{\sigma}{g+\delta}
$$

The two expressions are formally equivalent and each of them can be directly derived from the other. However, making $\delta$ explicit shows that the rate of savings $s$ in expression (3) cannot be assumed to be constant through time, unless we actually are in long run equilibrium, since it depends on $\beta$. What can be assumed to be constant— to be 'frozen' in our example above-is not total depreciation, but rather the rate of depreciation, whereas consumption of fixed capital crucially depends on the value of the stock of existing capital.

In fact, when computing net savings we subtract depreciation from gross savings, but while the rate of savings is applied to income, the rate of depreciation is applied to the existing stock of capital. In other words, we cannot simply 'hide' depreciation behind a 'net savings rate', but we have to explicitly account for it as in expression (4).

\footnotetext{
${ }^{12}$ Clearly, in the reality we will get the value of gross savings, capital stock, and income from national accounts, and then compute $\sigma$ and $\delta$ ex post.
} 
Figure 1 plots $\beta$ and $\beta^{*}$ for France in the period 1995-2014. ${ }^{13}$ The top panel includes all observations, while the bottom panel excludes outliers, i.e. extreme values, in order to show on a smaller scale the relation between the two.

As can be seen, $\beta^{*}$ is extremely volatile, and is almost always much lower than $\beta$. There are a few exceptions to this pattern; more specifically, $\beta^{*}$ can suddenly turn much higher than its actual value; this is what happened in 2009 (and then again in 2011) to Households and NPISH, due to the sharp fall of the rate of growth of income to almost zero $(0.22 \%)$. Moreover, when the rate of growh of income turns negative, so much so as to make $g+\delta$ negative as well-or, as is almost always the case for the General Government, when savings are negative- then $\beta^{*}$ can even turn negative. This is what happened to nonfinancial corporations in 2011. According to theory, when $\beta>\beta^{*}$, the former is bound to decrease — other things being equal — thanks to the inherent re-equilibrating forces.

This persistent difference can be due to another imprecision in Piketty's formulation. Recall that his definition of capital is the sum of the value of non-financial assets plus financial net worth. Depreciation applies to non-financial assets only, not to financial net worth as well. In the sequence of accounts, gross savings are identically equal to the sum of consumption of fixed capital, acquisitions less disposals of non-produced non-financial assets, and net lending/borrowing, which in its turn corresponds to the change in financial net worth-and can therefore be either negative or positive. ${ }^{14}$

$$
\dot{K}=\dot{K}_{N F}+\dot{K}_{F}=\sigma_{N F} Y-\delta K_{N F}+\sigma_{F} Y=\sigma Y-\delta K_{N F}
$$

where $K_{N F}$ is the value of non financial assets, $K_{F}$ is the value of financial net worth, and $K=K_{N F}+K_{F}$. Moreover, $\sigma_{N F}$ is the ratio of gross savings devoted to acquisitions less disposals of non financial assets to income; $\sigma_{F}$ is the ration of gross savings devoted to net acquisition less disposals of financial assets and liabilities; and $\sigma_{N F}+\sigma_{F}=\sigma$.

$$
g=\frac{\sigma Y-\delta K_{N F}}{K}=\frac{\sigma Y}{K}-\frac{\delta K_{N F}}{K}=\frac{\sigma}{\beta^{* *}}-\delta \kappa_{N F}
$$

where $\kappa_{N F}=K_{N F} / K$ is the proportion of total wealth given by the value of non financial assets. Hence, the 'long run equilibrium value' of $\beta^{* *}$ can be written as:

$$
\beta^{* *}=\frac{\sigma}{g+\delta \kappa_{N F}}
$$

\footnotetext{
${ }^{13}$ Data Source: https://www.insee.fr.

${ }^{14}$ For the time being, we disregard net capital transfers to the rest of the world. We will come back to this point later on.
} 
Expression (5) shows that $\beta^{* *}$ crucially depends on the weight of non-financial assets on total wealth. More specifically, the higher the ratio of non-financial to total wealth, the lower $\beta^{* *}$. Or, equivalently, the higher the ratio of financial net worth to total wealth, the higher $\beta^{* *}$. In other words, any increase in foreign credits/decrease in foreign debt makes $\beta^{* *}$ increase.

Figure 1 shows the evolution through time of $\beta$ and $\beta^{* *}$ once this correction is introduced.

\subsection{Correcting for other components of the change of value of non financial assets}

The change in the value of non-financial stocks is not given by acquisitions less disposals and consumption of fixed capital only. At the same time, the change in the value of financial net worth is not given by net lending/borrowing only. In this latter case, the additional component is given by capital transfers received from and paid to the rest of the world. ${ }^{15}$ In the former case, we have to add Revaluations (holding gains and losses), and Other volume changes and adjustments. Of course, since data concerning these two components come from non-financial balance sheets, while all other data from the sequence of accounts, we must accept the possibility of statistical discrepancy.

We therefore have to consider our expression for $\dot{K}$, and hence for both $\beta$ and its long run value, as the variation of the value of wealth net of revaluation, volume adjustments and net capital transfers:

$$
\begin{aligned}
& K_{n e t}=K-(N K T+R O A) \\
& \beta_{\text {net }}=\frac{K_{n e t}}{Y} \\
& \dot{K}_{n e t}=\sigma Y-\delta K_{N F}
\end{aligned}
$$

where $N K T$ are net capital transfers, and $R O A$ are revaluations and other adjustments.

Accordingly, expression (1) becomes:

$$
g=\frac{\sigma}{\beta^{* * *}}-\delta \kappa_{N F}
$$

\footnotetext{
${ }^{15}$ From Oecd Glossary of Statistical terms: "Capital transfers are unrequited transfers where either the party making the transfer realizes the funds involved by disposing of an asset (other than cash or inventories), by relinquishing a financial claim (other than accounts receivable) or the party receiving the transfer is obliged to acquire an asset (other than cash or inventories) or both conditions are met. Capital transfers are often large and irregular but neither of these are necessary conditions for a transfer to be considered a capital rather than a current transfer."
} 
and hence:

$$
\beta^{* * *}=\frac{\sigma}{g+\delta \kappa_{N F}}
$$

In other words, we have to consider the presence of a residual $\varepsilon$, which does not depend on individual savings or investment decisions. Results are shown in Figure 1.

There is no correlation whatsoever between $\beta$ and its 'long run value', however computed. Nor is it possible to use the latter to anticipate the movements of the former. Moreover, there is a huge asymmetry between non-financial assets and financial net worth, since the latter is simply the (consolidated) balance of financial assets and liabilities, i.e. the net position towards the rest of the world. It can hide enormous assets and liabilities, which cannot be considered in the present framework. Moreover, Piketty attaches great importance to inherited wealth, but this phenomenon is also far from apparent in the present framework.

In this framework, disposable income simply becomes the numéraire according to which national wealth can be measured for intertemporal and inter-country comparisons. ${ }^{16}$ As can be seen from Figure 2, $\beta_{N F}$, i.e. the ratio of non-financial wealth to disposable income, is the main component of $\beta$. This is especially true when we look at total economy, rather than general government and households only.

\subsection{An alternative interpretation}

The empirical exercise carried out in the previous pages should have clarified that it is hard to attach a descriptive or predictive meaning to $\beta$ 's long run equilibrium value, however computed. In the same way, it is hard to attach to $\beta$, as Piketty computes it, any role in disclosing relevant growth-theoretic or distributional issues. So much so that, as stated above, the idea is that of showing how the accumulation of stocks is generated by flows through savings, and not how accumulated stocks generate flows of income.

What the data actually tell us is that income has been growing at the same pace as disposable income in the second half of the 1990s, then started growing faster in the 2000s, dropped in 2008, recovered in 2009 and 2010, and then started growing slower than disposable income, a trend which is still ongoing. The trend is apparent when looking at both $\beta$ and $\beta_{N F}$. If we focus solely on $\beta_{N F}$, we can extend our time series back to 1978 . Results are presented in Figure 3. Our series starts, in the very first year, with a positive trend. Then the value of financial assets have been growing less than disposable income in the first half of the 1980s; the ratio stabilized in the second half of the century, to decrease again in the 1990s. In 1998 non-financial wealth started accelerating with respect

\footnotetext{
${ }^{16}$ With all the drawbacks stressed in the previous sections.
} 
Figure 1: $\beta$, current values versus LR equilibrium levels (1995-2014)

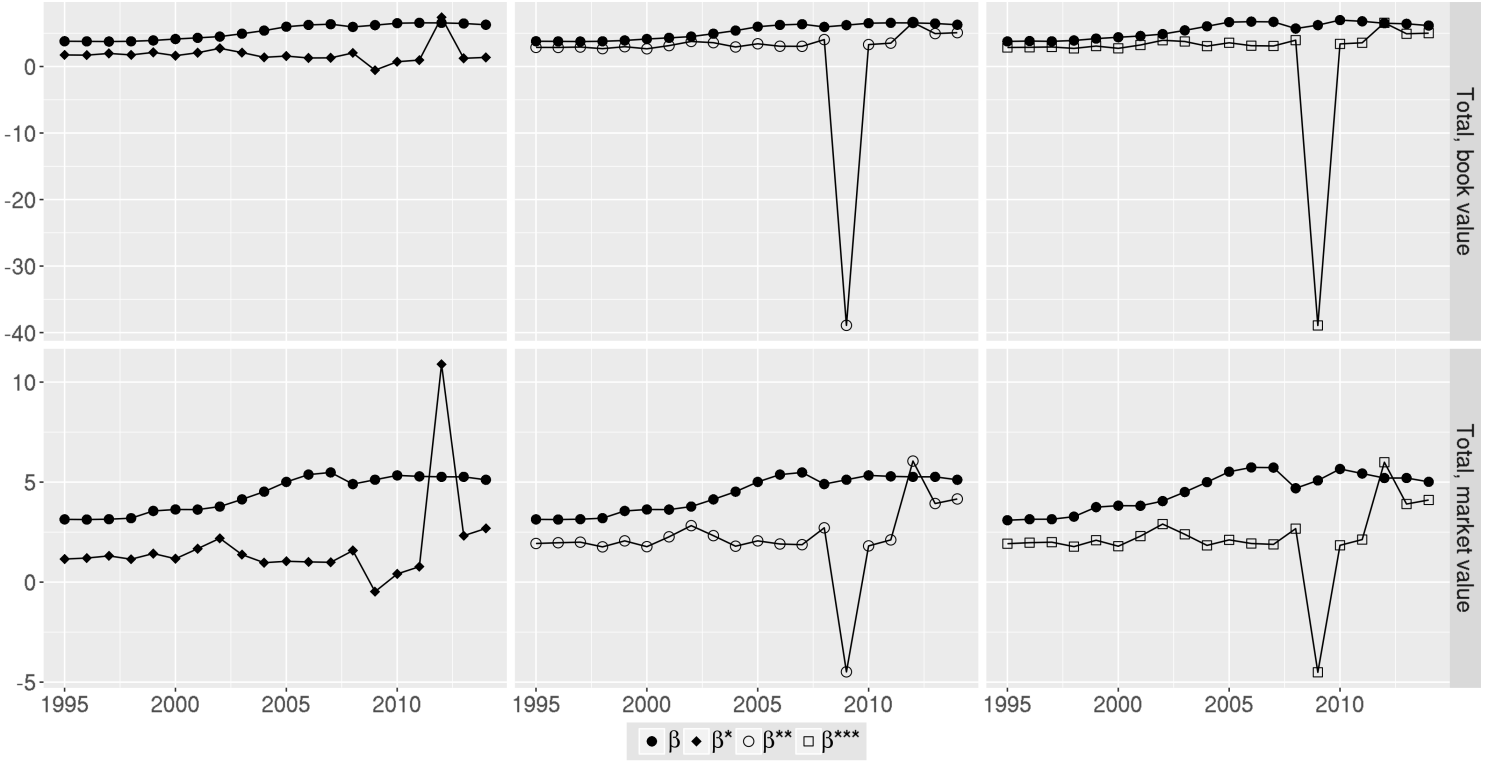

Zoom in selected region

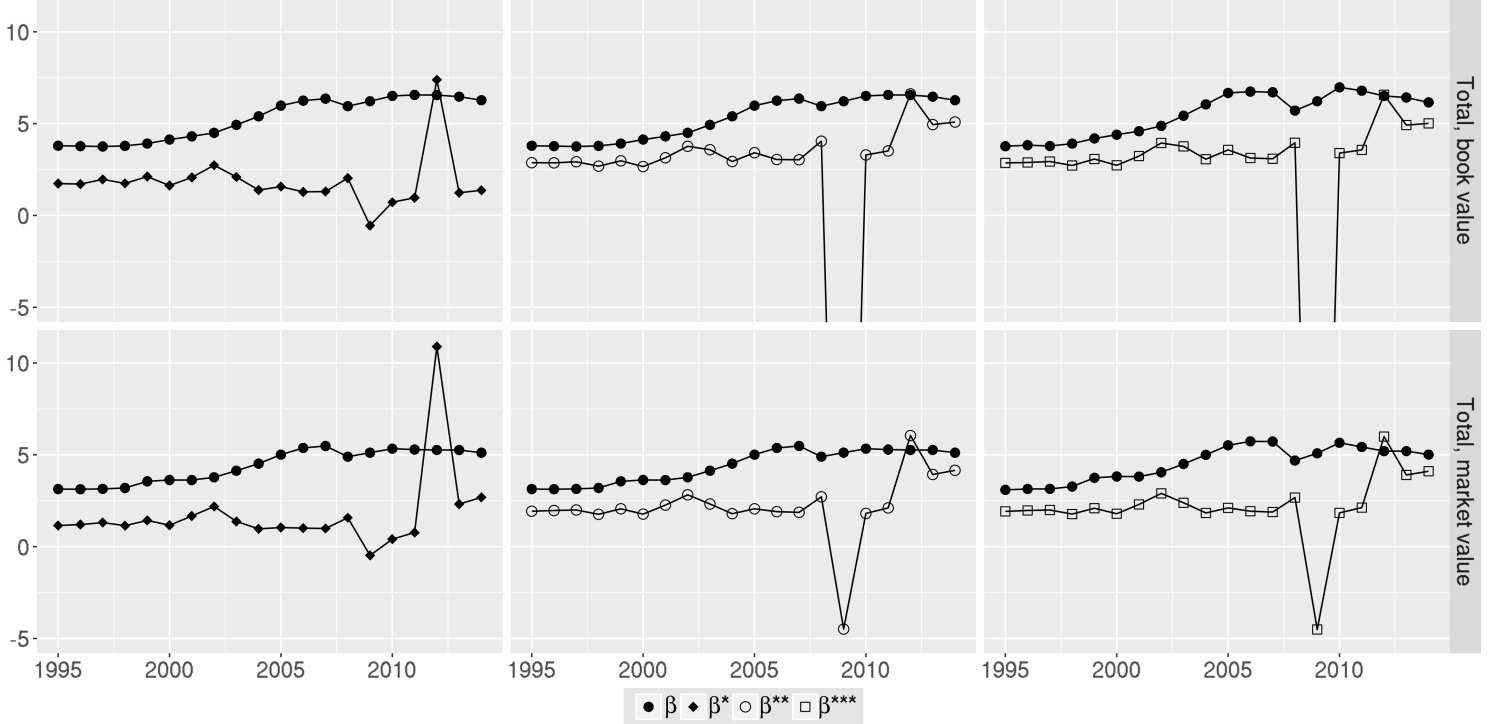

Source: own computations based on INSEE

to disposable income, with an extraordinary increase of the ratio that stopped only with the crisis.

Figure 4 reproduces the results of Figure 3, but disaggregated by institutional sec- 
Figure 2: Capital/income ratio for total wealth, financial net worth and non-financial assets (1995-2014)

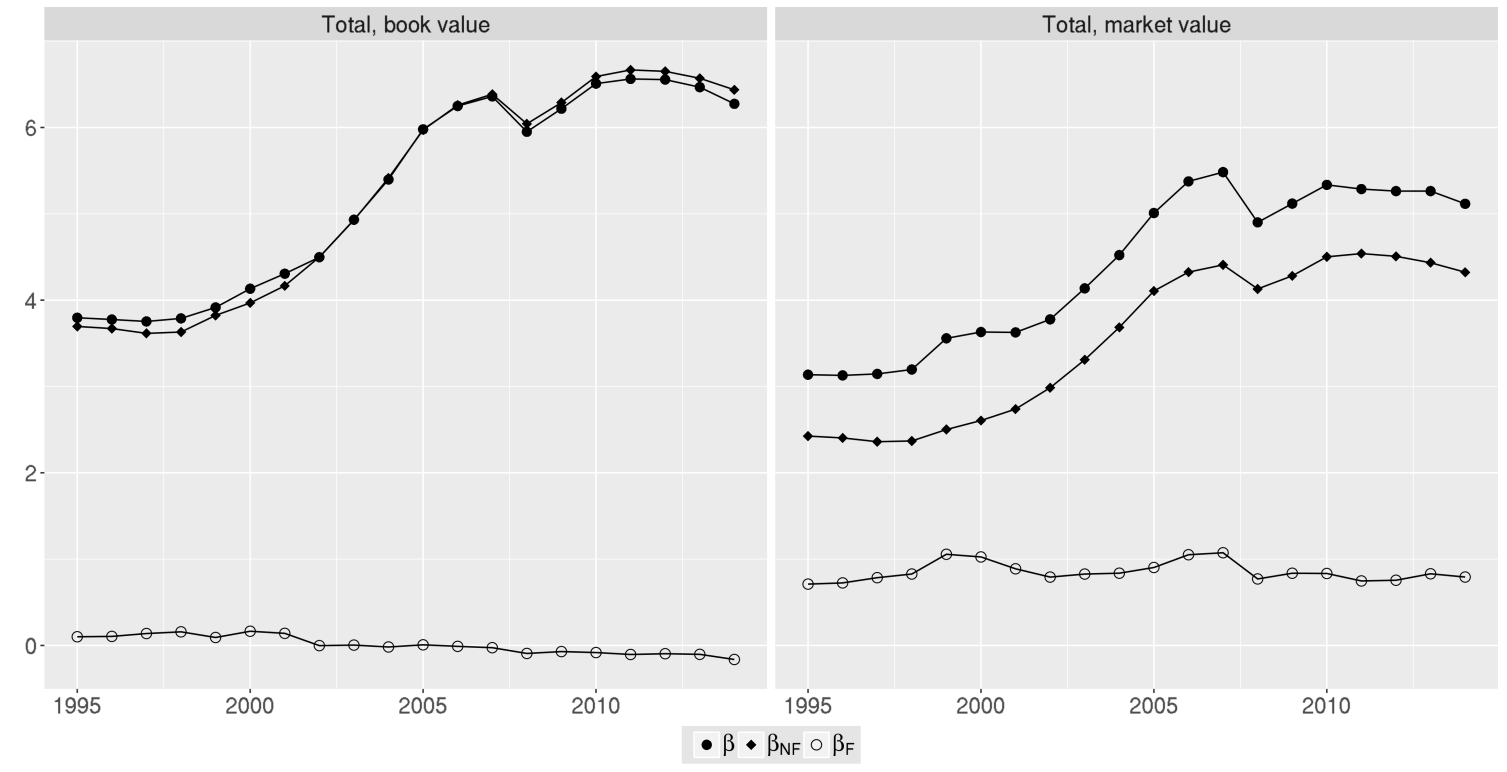

Source: own computations based on INSEE

tors. Households and NPISH and General Government show the same pattern as the total economy. Capital/output ratios for financial corporations were quite low up to 1997, then started growing but oscillating in the decade between 1998 and 2007. After a drop in 2008, the ratio started increasing sharply again from 2009 onwards.

On the contrary, non-financial corporations were characterized by a strongly increasing, and very high, capital/income ratio up to 1981. Then, the ratio dropped dramatically in the period between 1982 and 1986, smoothly increased up to 1995 and then decreased up to 1997, when it started a new sharp increase. Such an increasing trend came to a halt only in 2013 — with the exceptions of 2007 and 2010 — and is now decreasing.

However, the general trend is of course determined by what happened in the institutional sector of Households and NPISH, which owns the majority of non-financial assets (see Figure 11).

What happened in the ten years between 1998 and 2007 ?

An answer can be given by looking at income as GDP, i.e. as the sum of gross operating surplus (profits, roughly speaking) and wages as they are paid-i.e. generated-in production activity. In this case, as in the case of GNI, we are dealing with a definition of income that has to do with income produced starting from existing stocks, i.e. with the 
Figure 3: Value of $\beta$ for non-financial assets (1978-2014)

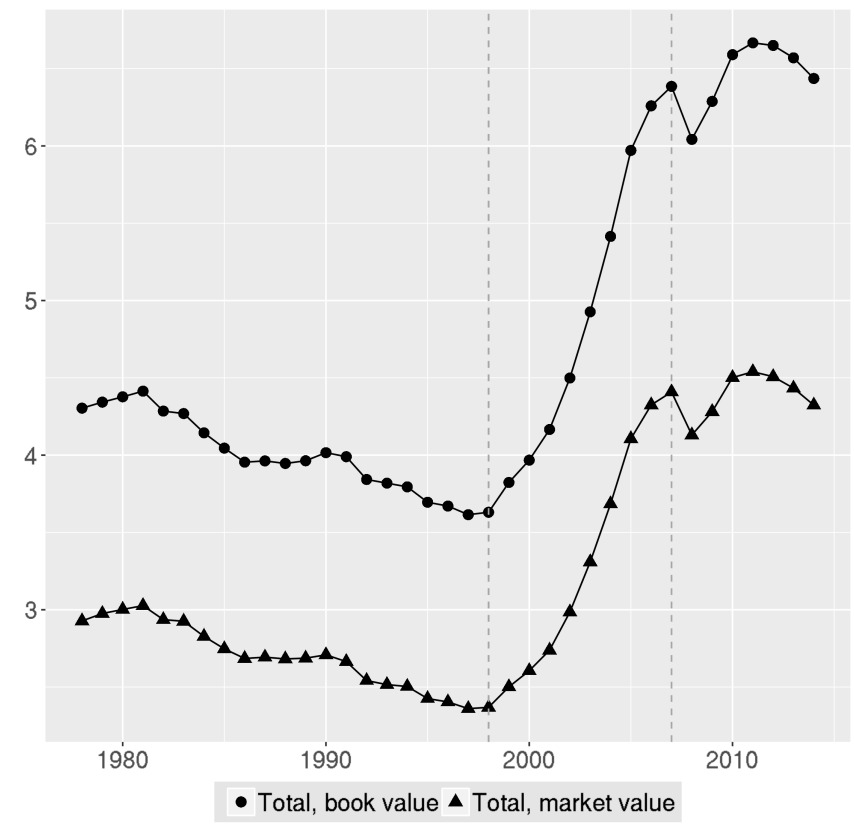

Source: own computations based on INSEE

linkage between accumulation and the flows it allows to generate. However, differently from GNI, we are looking at primary income as it is paid, not received. We are not interested in seeing how recipients spend their income, but in the way in which such an income is generated in production activity. In other words, we are asking ourselves how much income can be squeezed, year after year, out of the given stock of existing wealth. Moreover, differently from GNI, GDP does not include financial income.

The accounting identity summarizing the Generation of Income Account, whose balancing item is precisely GDP (YNF), can be written as: The accounting identity summarising the Generation of Income Account, whose balancing item is precisely GDP $\left(Y_{N F}\right)$, can be written as:

$$
Y_{N F} \equiv \Pi+W
$$

where $\Pi$ is Operating surplus and mixed income plus Taxes less subsidies on products and $W$ is Compensation of employees.

Hence, restricting our attention to non financial capital and income, $\beta_{N F}$ can be written as:

$$
\beta_{N F}=\frac{K_{N F}}{\Pi+W_{R}}=\frac{K_{N F}}{\pi K_{N F}+\frac{W_{R}}{K_{N F}} K_{N F}}=\frac{1}{\pi+\frac{w L}{K_{N F}}}=\frac{1}{\pi+\frac{w}{\lambda}}=\frac{1}{\frac{\pi \lambda+w}{\lambda}}=\frac{\lambda}{\pi \lambda+w}
$$


Figure 4: Value of $\beta$ for non-financial assets by institutional sector (1978-2014)
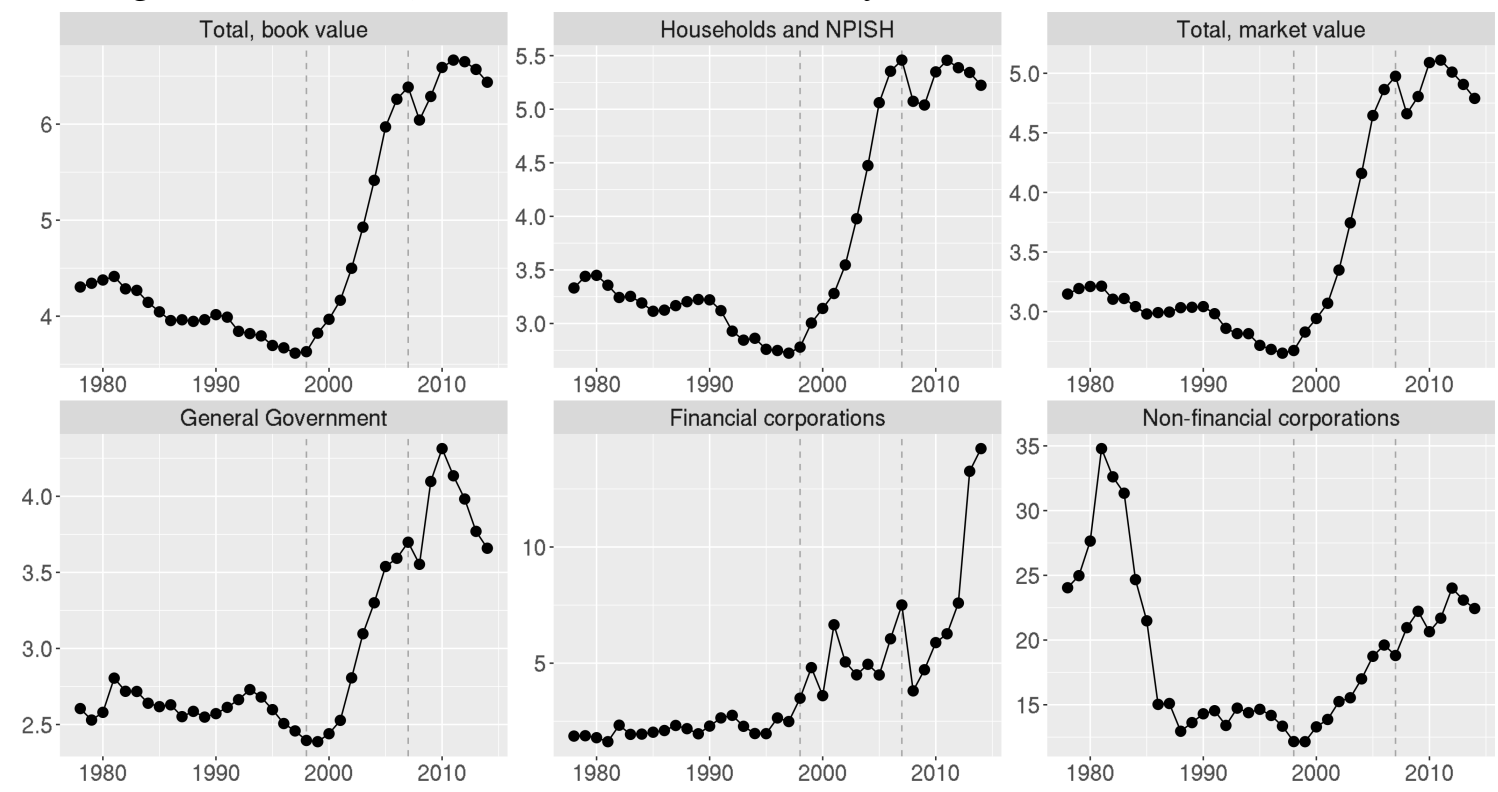

Source: own computations based on INSEE

Expression (7) shows that capital/output ratio, when computed in this way, depends on $\lambda=K_{N F} / L$, i.e. the degree of mechanization, on the wage rate $w=W / L$, and the rate of profits $\pi=\Pi / K_{N F}$. When $\pi$ and $w$ increase, $\beta_{N F}$ decreases; conversely, when $\lambda$ increases, $\beta_{N F}$ increases as well. However, all magnitudes we are dealing with are expressed in current prices. Hence, in this case the degree of mechanization is not a measure of the quantity of capital goods operated by each worker, but rather of the value of such capital. Results are shown in the leftmost panel of Figure 5. Also in this case, the sharp increase of capital/output ratio between 1998 and 2008 is apparent.

The middle panel of Figure 5 shows the evolution of $\pi, \lambda$ and $w$. The co-movement of $\beta_{N F}$ and $\lambda$ is apparent. Is this sharp increase in the degree of mechanization due to an increase in the value of capital or to a decrease in labor? The rightmost panel of the Figure shows the dynamics of GDP, total wages and profits, labor ${ }^{17}$ and non-financial capital. As can be seen, while the quantity of labor was almost constant through time, the value of non-financial assets sharply increased between 1998 and 2007.

It is also interesting to look at sectoral values of $\lambda$, to see whether its increase is generalized or limited to certain institutional sectors. Results are shown in Figure 6. The

\footnotetext{
${ }^{17}$ Labor is measured in full time equivalent (FTE) units, in order to make the values of $\lambda$ comparable through time.
} 
Figure 5: Evolution of main GDP component and related magnitudes (1978-2014)
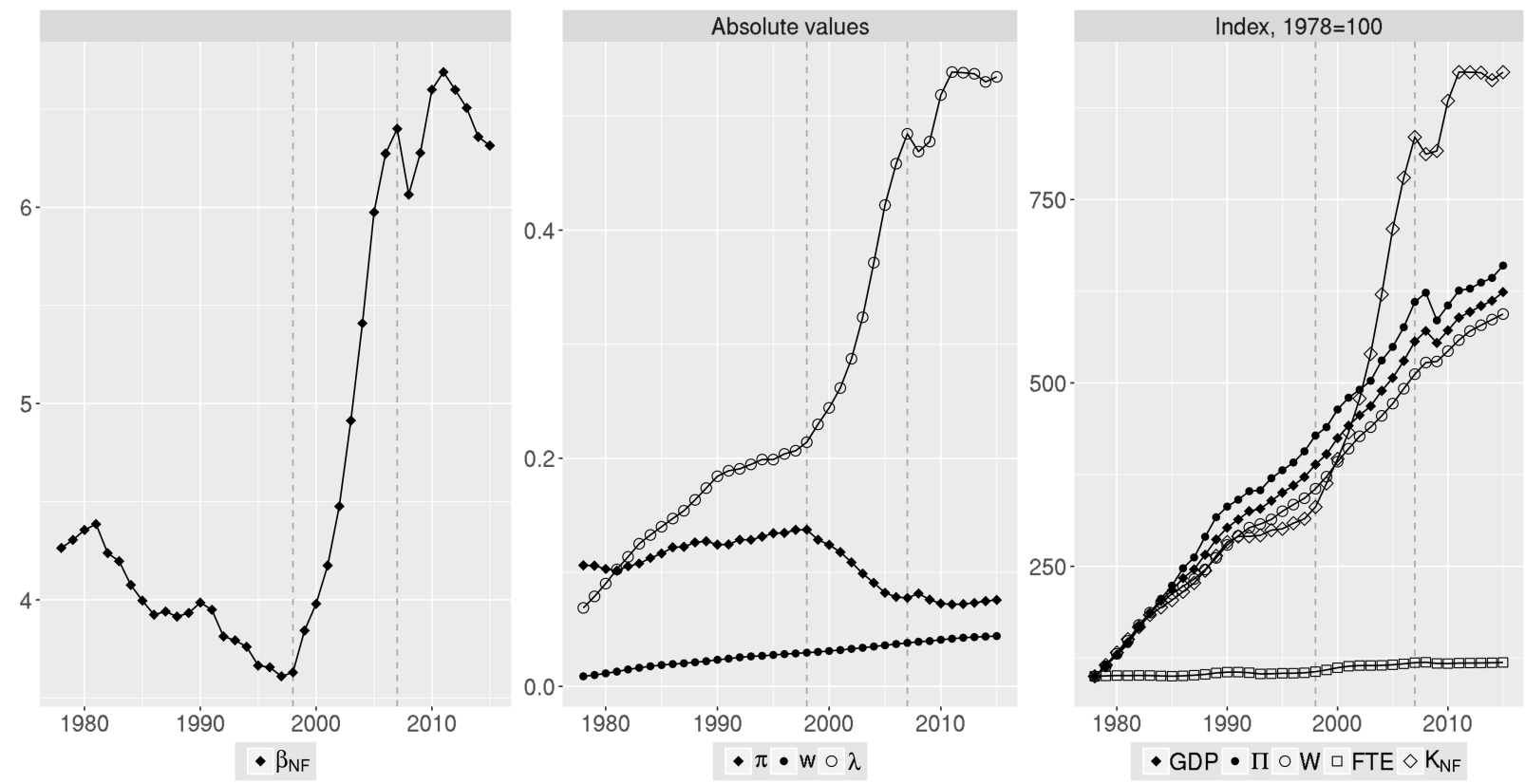

Source: own computations based on INSEE

dynamics of $\lambda$ are qualitatively the same in all sectors. However, the scale is different. First of all, it should be noted that Households and NPISH is the sector characterized by the highest degree of mechanization and by the greatest increase between 1998 and 2007. It is also apparent by looking at the three top panels that consolidated totals-both for all sectors and for Households and NPISH and General Government only-is mainly determined by this sector. Hence, unincorporated businesses are characterized by a higher degree of mechanization than corporations. The dynamics of $\lambda$ for General Government, Non-financial corporations and Financial corporations are very similar, even though the latter had a lower $\lambda$ before 1998, and grew more between 1998 and 2007.

In order to give an interpretation to these figures, it is necessary to understand to what extent this increase is due to volume or price effects. The sequence of non-financial accounts is valued at current prices, so that we have to turn to a different data source. More specifically, we are using national accounts data as presented in the AMECO Database. ${ }^{18}$ Figure 8 shows the evolution through time of Gross Fixed Capital Formation, both at cur-

\footnotetext{
${ }^{18} \mathrm{https}$ ://ec.europa.eu/info/business-economy-euro/indicators-statistics/economic-databases/macroeconomic-database-ameco/ameco-database_en is the annual macro-economic database of the European Commission's Directorate General for Economic and Financial Affairs.
} 
Figure 6: Degree of mechanisation by institutional sector (1978-2014)
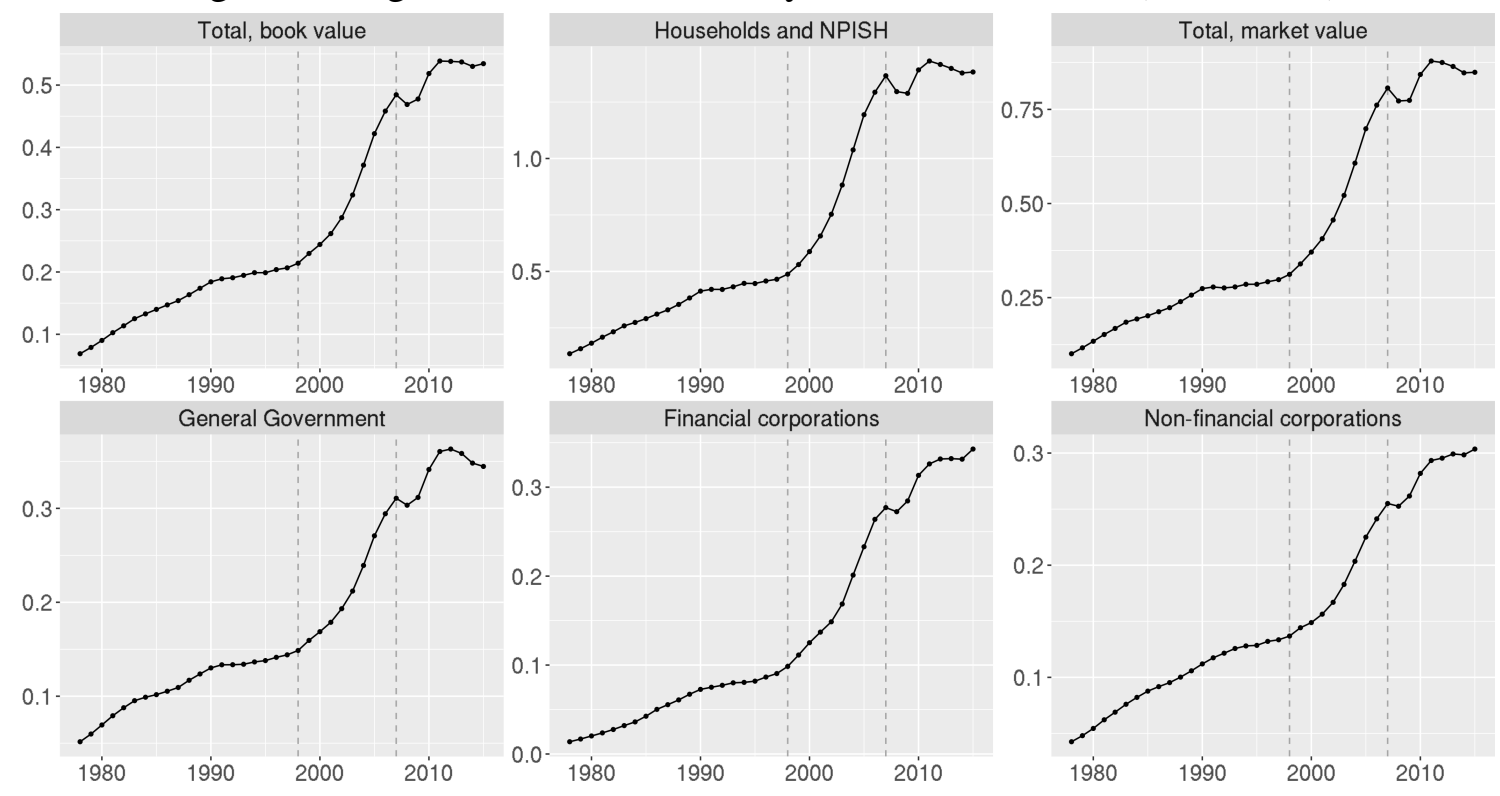

Source: own computations based on INSEE

rent and constant prices, and of Net Fixed Capital Stock. Whereas the dynamics of investments in fixed capital at constant prices was almost flat over the whole period, including the years between 1998 and 2007, gross fixed capital formation at current prices has been constantly increasing, especially in the decade we are examining. This means that volume changes have not been particularly relevant in determining the observed changes in the value of the stock of non-financial assets. It is the price of non-financial assets that underwent a sharp increase over time. This means that, as time goes by, new physical capital items are more and more expensive. This can be due to the fact that new machines and equipment become more and more complex and technologically advanced, and hence more expensive, or to some other unobserved reason.

More information can be gathered by looking at the same figures, but disaggregated according to the branch producing the different fixed capital items. This is done in Figures 8 and 9. Looking at the graphs, we can immediately notice a difference between the top panels-dealing with Construction Products, disaggregated into Dwellings and NonResidential construction and Civil Engineering-and the bottom panels-dealing with Metal Products and Machinery, disaggregated into Equipment and Transport equipment.

Starting from the latter, we can see that during the entire period considered here gross fixed capital formation at current prices and constant prices has been following the same 
Figure 7: Gross fixed capital formation (1978-2014)

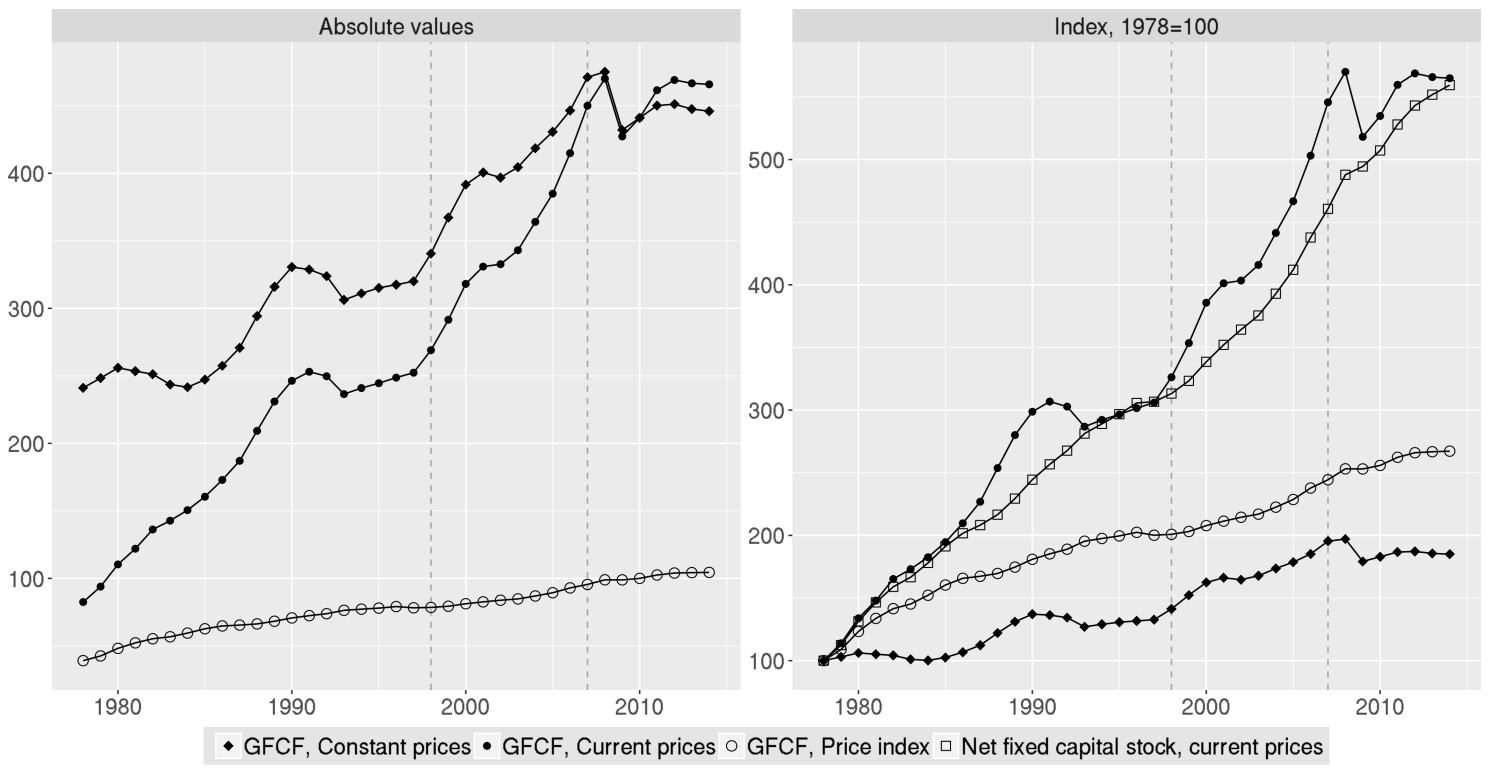

Source: own computations based on AMECO

trend as GFCF at constant prices; in other words, volume effects did prevail—even though, looking at indexes (Figure 9) a faster growth of current prices GFCF does emerge as a generalized tendency, i.e. not limited to the decade under examination, particularly in the case of transport equipment. Moreover, GFCF growth in the years between 1998 and 2007 followed the same dynamics as the previous years, with a sharp decrease only after the crisis.

When looking at construction the picture is completely different. First, we have to notice that the dynamics of GFCF in this case has been much more unstable over the whole period considered, especially in the case of constant prices. The decade between 1998 and 2007 brought about a significant turnaround, with a sharp increase of both current and constant prices GFCF. However, in this case gross fixed capital formation was much higher at constant than at current prices up to 1997. From 1998, the gap has been almost completely closed, meaning that prices of construction output has been increasing much more than its volume. This is apparent for the case of both Dwellings and Non-Residential Construction, but especially strong in the latter case.

The conclusion we can draw from this analysis is that capital/income ratios increased between 1998 and 2007 due to the sharp increase in the value of the stock of non-financial assets, which in turn was driven by an increase of the degree of mechanization brought 
Figure 8: Gross fixed capital formation by producing branch of investment goods (19782014)

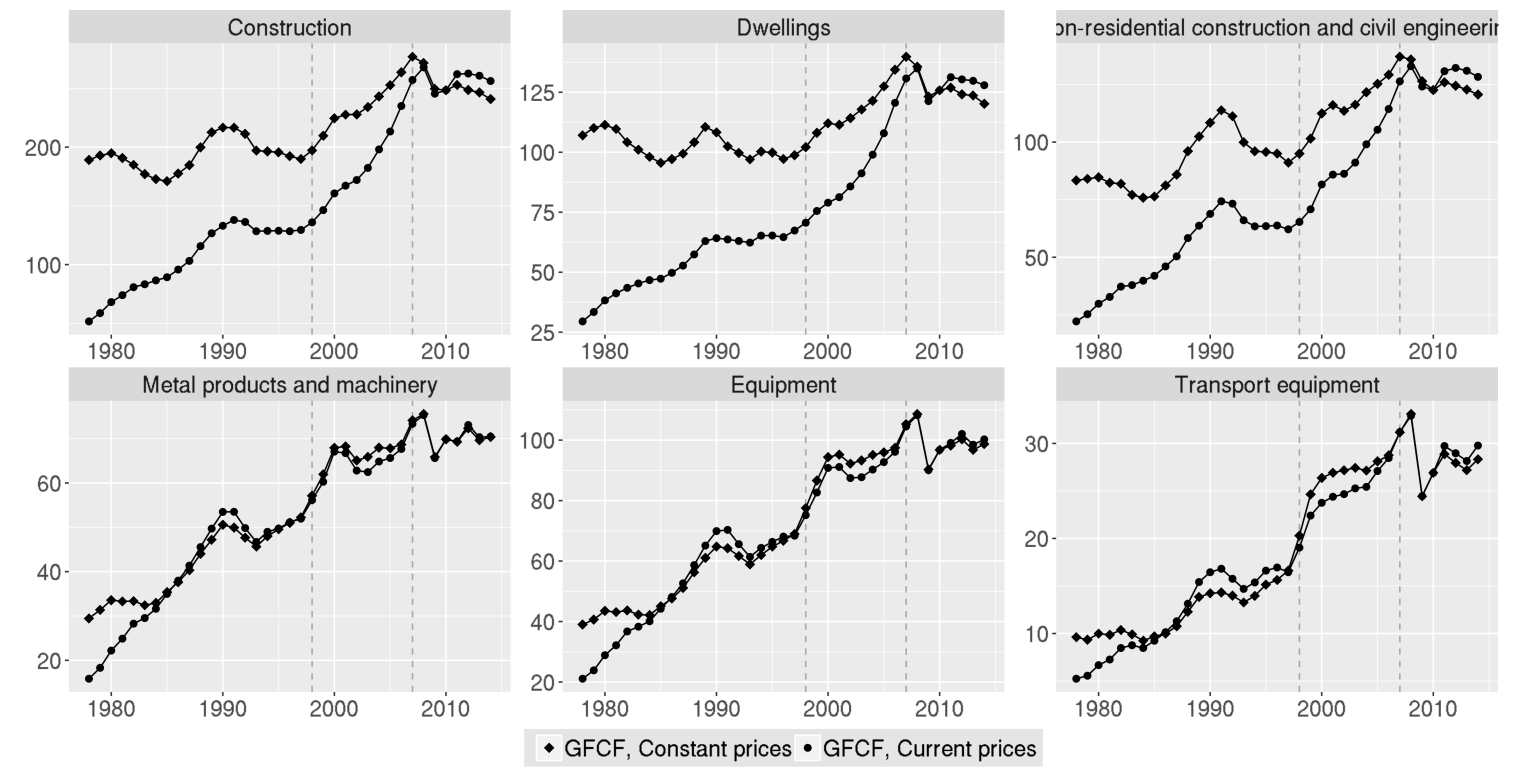

Source: own computations based on AMECO

about by price, rather than volume, effects. This increase in fixed capital prices was due to the increase in construction prices, which could be associated to the construction bubble that originated the crisis.

The relevance of construction in determining GFCF is also apparent when looking at Figure 10, showing the composition of gross fixed capital formation by producer branch both at constant and current prices.

Finally, a word should be devoted to the sectoral composition of the different kinds of income and in the ownership of non-financial assets, shown by Figure 11. Apparently, GNI and disposable income show quite similar compositions, as compared to that of GDP. The main difference is given by the relative weight of Households and NPISH and General government, due to transfers for taxes and social contributions. Since the weight of General Government is higher in the case of disposable income, there are positive net transfers from Households and NPISH to the Government. The composition of GDP is radically different. Of course, this is mainly due to wages, which are generated both by unincorporated businesses and corporations, but are received by households only. Stressing these differences is important for making clear that choosing one or another definition of income entails relevant consequences on the analysis to be carried on, and hence the choice must 
Figure 9: Gross fixed capital formation by producing branch of investment goods (19782014). Index, $1978=100$

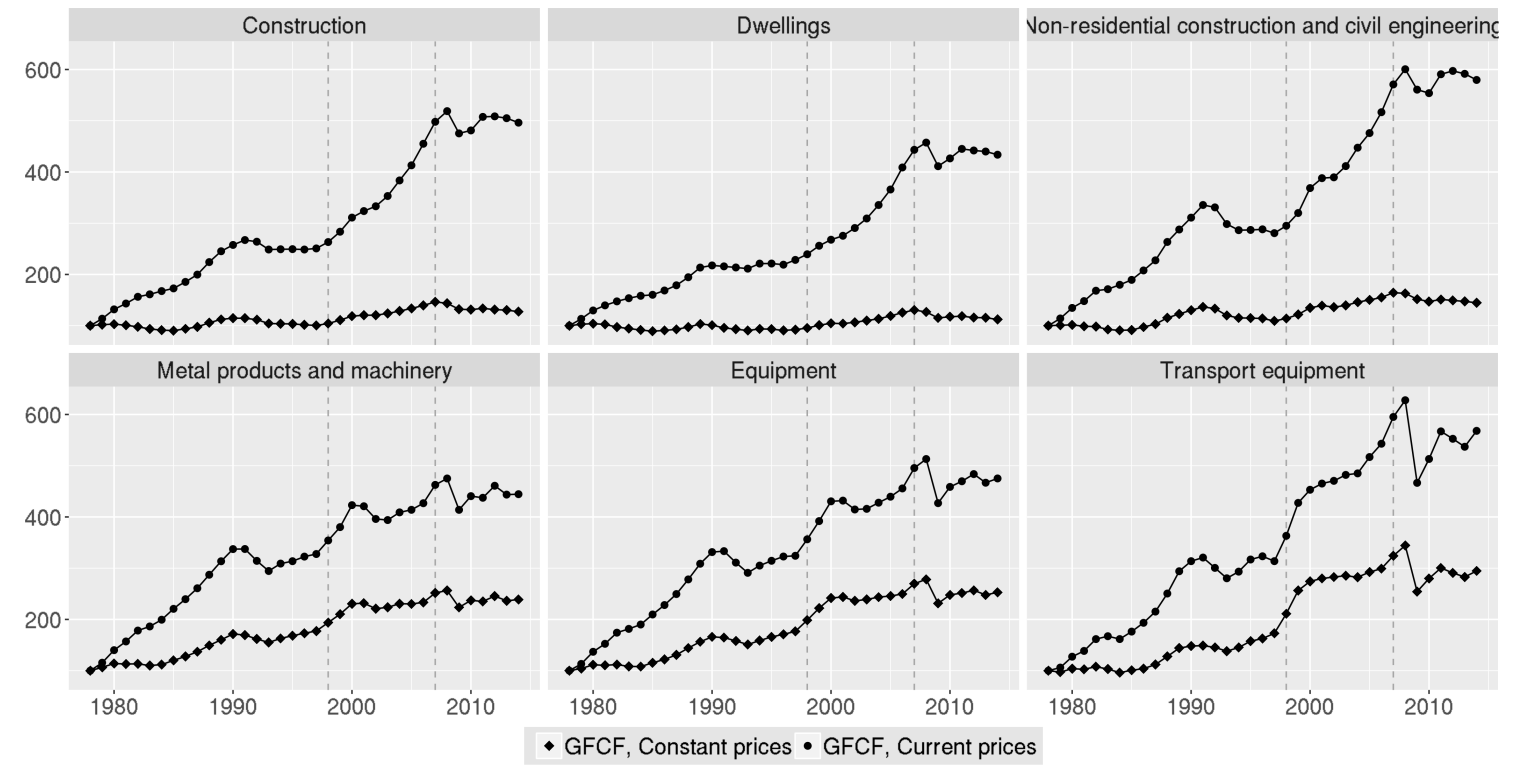

Source: own computations based on AMECO

be carefully taken on the basis of the phenomenon that is to be dealt with.

\section{Conclusions}

The analysis carried out in the previous pages aims at singling out some theoretical and empirical issues of Piketty's analysis of capital/output ration, and of the conclusions drawn on the basis of his assumptions.

First of all, Piketty's wealth/income ratio is far from fitting the capital/output ratio that has been one of the mainstays of growth theory, both classical and neoclassical. It is therefore hard to switch from theory to data, and interpret such a ratio as economic theory has traditionally been doing. Piketty's ratio is definitely not a measure of capital intensity as determined by the technique in use, nor a proxy for it.

Second, the second fundamental law of capitalism, i.e. the 'long run equilibrium value' of $\beta$, suffers from the usual neoclassical bias: how can we define a long run equilibrium if this equilibrium itself is continually shifting through time? Either the system is, and has always been, in equilibrium, or the very notion of equilibrium itself if meaningless.

Third, and connected to the previous points, Piketty defines capital as the sum of the 
Figure 10: Composition of Gross fixed capital formation by producing branch (1978-2014)

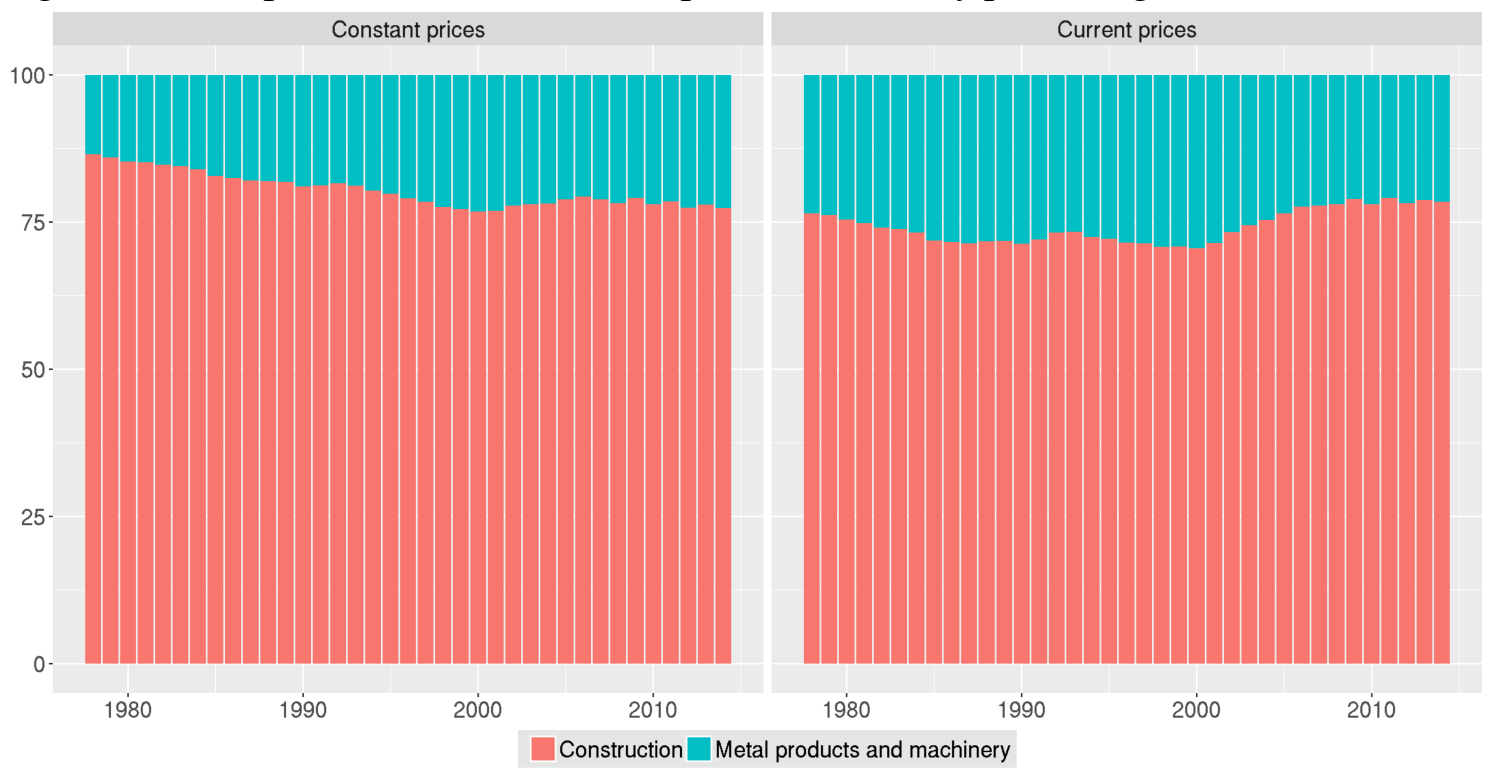

Source: own computations based on AMECO

value of non-financial assets and financial net worth. Besides the fact that the two kinds of 'capital'-financial and non-financial—are radically different in their nature, it emerges that financial net worth is, precisely, a netting of financial assets and liabilities towards the rest of the world, and in fact is simply the net lending/borrowing of the economy. Again, disregarding the role of financial and most of all non-financial corporations leads to biased results.

Turning to Piketty's empirical strategy, the first drawback is represented by the definition of national wealth as the sum of wealth owned by Households and NPISH and the General government. As Piketty himself stresses, disregarding corporations, both financial and non-financial, makes no difference only in the case in which Tobin $Q$ is equal to 1 . In all other cases, the difference is extremely relevant, especially if financial corporations also include banks and, specifically, the Central Bank. Given that Piketty devotes more than a few lines to the issue of public debt, this seems to lead to biased conclusions.

Second, the notion of income chosen by Piketty is that of GNI. However, for the kind of analysis he is carrying on, disposable income seems to be the most appropriate income concept to be used, since he focuses on how income is spent-and hence on how savings determine the evolution of the stock of total wealth.

Looking at the actual value $\beta$ as defined by Piketty-with some corrections due to the 
Figure 11: Composition of GDP, GNI, disposable income and non-financial assets ownership by institutional sector (1978-2014)

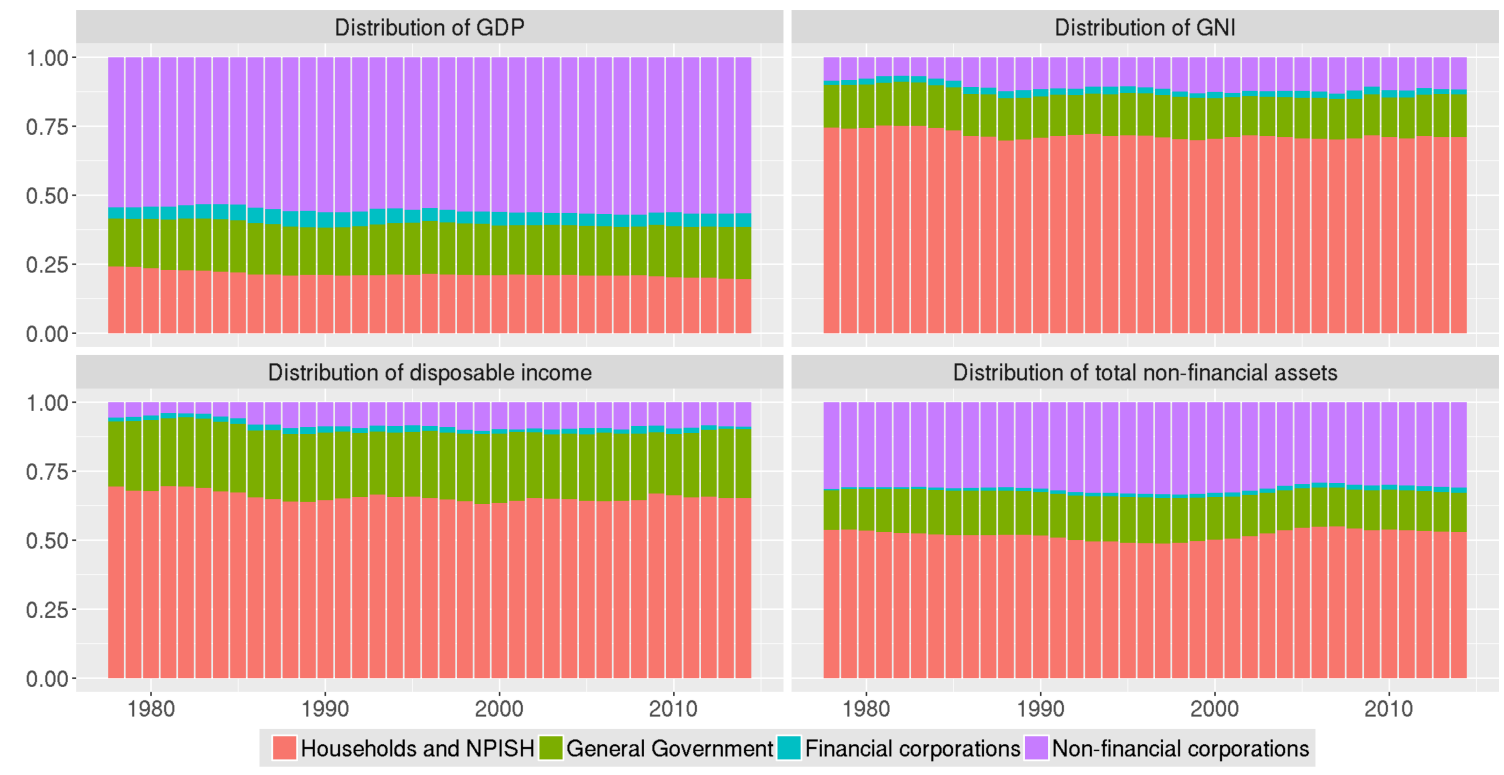

Source: own computations based on INSEE

fact that the change in the value of capital in national accounts is not given by savings only-as compared to its long run value, no correlation emerges between the two. The only apparent result is that $\beta$ has been increasing in the years between 1998 and 2007, and after that has been constantly declining.

In order to better understand this phenomenon, it is useful to look at it from a different point of view, and therefore change the definition of both income and wealth. Whereas the latter has to be defined as non-financial assets only-and actually, we have seen that financial net worth is only a tiny fraction of the total-the concept of income that seems to be relevant is that of GDP. In fact, what we want to assess is the capacity of the system to generate surplus, and hence primary income different than property income, through production activity.

When looked at in this way, the sharp increase of capital/output ratio in the decade between 1998 and 2007 can be explained by a huge increase of the 'degree of mechanization', i.e. the capital/labor ratio. However, this increase is not due to a volume, but rather to a price effect. Looking at GFCF, we can see that it increased, over the period considered, much more at current rather than constant prices. This is especially apparent when looking at Construction. This suggests that the observed capital/output dynamics 
might depend on the housing bubble, so much so that the positive dynamics came to a halt precisely in 2007, when the bubble burst.

\section{References}

Bliss, C. J. (1975). Capital Theory and the Distribution of Income. North Holland, Amsterdam.

Cohen, A. J. and Harcourt, G. C. (2003). Whatever Happened to the Cambridge Capital Theory Controversies? Journal of Economic Perspectives, 17(1):199-214.

Domar, E. D. (1948). The Problem of Capital Accumulation. American Economic Review, 38(December):777-794.

Garbellini, N. and Wirkierman, A. L. (2014). Piketty versus Pasinetti: A Comment on Taylor. International Journal of Political Economy, 43(3):35-43.

Harcourt, G. C. (1972). Some Cambridge Controversies in the Theory of Capital. Cambridge University Press, Cambridge.

Harrod, R. F. (1939). An Essay in Dynamic Theory. The Economic Journal, 49(193):1433.

Harrod, R. F. (1948). Towards a Dynamic Economics. Macmillan, London.

Levhari, D. (1965). A nonsubstitution theorem and switching of techniques. Quarterly Journal of Economics, 79:98-105.

Levhari, D. and Samuelson, P. A. (1966). The nonswitching theorem is false. Quarterly Journal of Economics, 80(4):518-519.

Pasinetti, L. L. (1966). Changes in the Rate of Profit and Switching of Techniques. The Quarterly Journal of Economics, 53(4):503-517.

Pasinetti, L. L. (1969). Switches of technique and the "rate of return" in capital theory. Economic Journal, 79:508-531.

Pasinetti, L. L. (1974). Growth and Income Distribution - Essays in Economic Theory. Cambridge University Press, Cambridge.

Pasinetti, L. L. (1977). Lectures on the Theory of Production. Columbia University Press, New York. 
Pasinetti, L. L. (1981). Structural Change and Economic Growth. Cambridge University Press, Cambridge.

Petri, F. (2007). Review of Capital Theory. European Journal of the History of Economic Thought, 14(September):597-607.

Piketty, T. (2014). Capital in the Twenty-First Century. The Belknap Press of Harvard University Press, Cambridge, Massachusetts - London, England.

Piketty, T. (2015a). About Capital in the Twenty-First Century. American Economic Review: Papers \& Proceedings, 105(5):48-53. Available online.

Piketty, T. (2015b). Capital in the Twenty-First Century: a multidimensional approach to the history of capital and social classes. British Review of Sociology, 65(4):736-747. Available online.

Piketty, T. and Zucman, G. (2014). Capital is back: Wealth-income ratios in rich countries 1700-2010 - data appendix. Available online.

Robinson, J. V. (1953). The production function and the theory of capital. Review of Economic Studies, 21:81-106.

Samuelson, P. A. (1962). Parable and realism in capital theory: the surrogate production function. Review of Economic Studies, 29:193-206.

Samuelson, P. A. (1966). A Summing Up. Quarterly Journal of Economics, 80(November):568-583.

Solow, R. M. (1956). A Contribution to the Theory of Economic Growth. The Quarterly Journal of Economics, 70(1):65-94.

Solow, R. M. (1963). Capital Theory and the Rate of Return. North-Holland, Amsterdam.

Solow, R. M. (2014). Thomas Piketty is right. Available online.

Sraffa, P. (1960). Production of Commodities by Means of Commodities. Cambridge University Press, Cambridge.

United Nations (2009). System of National Accounts 2008. UN Statistical Division, New York.

United Nations Statistics Division (2016). Undata glossary. Available online. 